\title{
Strength Prediction and Reliability of Brittle Epoxy Adhesively Bonded Dissimilar Joint
}

\author{
Mohd Afendia, ", M.S. Abdul Majid ${ }^{\mathrm{a}}$, Ruslizam Daud ${ }^{\mathrm{a}}$, A. Abdul Rahman ${ }^{\mathrm{b}}$, \\ Tokuo Teramoto
}

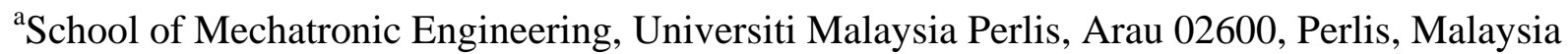
${ }^{\text {b} P E T R O N A S ~ C h e m i c a l ~ F e r t i l i s e r ~ K e d a h ~ S d n ~ B h d, ~ K m ~ 3, ~ J a l a n ~ J e n i a n g, ~ G u r u n ~ 08300, ~ K e d a h, ~}$ Malaysia

${ }^{\mathrm{c}}$ Graduate School of Systems and Information Engineering, University of Tsukuba,

Tennoudai 1-1-1, Tsukuba, Ibaraki 305-8573, Japan

*Corresponding author. Tel.: +604-988-5162; fax: +604-988-5245

E-mail address: afendirojan@unimap.edu.my (M. Afendi) 


\section{Abstract}

This paper deals with strength and failure prediction as well as reliability issues of adhesive joints of brittle epoxy bonding two dissimilar adherends. Effects of bond thickness and scarf angle upon the strength of such joints are also addressed. Three kinds of adhesive joints, i.e., butt, scarf and shear joints are considered. It is found that the strength prediction of various adhesive joints under consideration can be done by establishing interface corner toughness, $H_{c}$ parameter. For adhesive joints with an interfacial crack, fracture toughness, $J_{c}$ or interfacial toughness, $K_{c}$ can be used as a fracture criterion depends on the fracture type observed. The predicted strengths based on these fracture criteria (i.e. $H_{c}, J_{c}$ and $K_{c}$ ) are in good agreement with experimental data obtained. Weibull modulus is a suitable parameter to define the strength reliability of adhesive joints. From experimental data, scarf joint of $45^{\circ}$ is identified to be preferable since it satisfies both outstanding load-bearing performance and tolerable reliability. In addition, Weibull statistical method has made possible the strength reliability determination of non-cracked adhesive joints.

Key words: bond thickness; singularity; dissimilar adherends; interface mechanics; prediction; reliability 


\section{Introduction}

Integrity and reliability of adhesive joints are very crucial in structural engineering and industrial applications. Therefore, destructive testing and stress analyses are essential in predicting the performance of adhesive joints. In general, strength and failure predictions of adhesive joints are either based on strength of materials or fracture mechanics approach [1]. Nevertheless, these predictions remain tolerably difficult due to lack of sufficient criteria with sound physical basis [2, 3]. In the case of adhesive joints bonded with relatively rigid brittle adhesive resin, so far, there is some evidence that presents the relation between strength and bond thickness of such joints can be satisfactorily estimated by means of stress singularity based fracture parameters, i.e. interface corner toughness, $H_{c}$ or critical fracture energy, $G_{c}$.

Some investigators validated experimentally the $H_{c}$ stress intensity factor parameter. For instance, Reedy and Guess [4] accurately predicted the dependence of cylindrical butt joint's strength upon the bond thickness by using $H_{c}$ approach. They also reported the difference of measured strength between joints with steel-steel and aluminium-aluminium adherends. This "adherend's stiffness effect" has been correlated to the difference in order of stress singularity at the interface corner. Further, Reedy [5] examined the connection between interface corner and interface fracture mechanics approaches using both asymptotic and finite element solutions. The applicability of both techniques to the problem of unstable failure which initiates from an interface corner has been validated. 
In another study, Akisanya and Meng [6] used their experimental results to support the application of $H_{c}$ as a fracture initiation criterion at the interface corner of bonded joints. Using elastic-plastic finite element analysis, they concluded that in order for $H_{c}$ to be applicable, failure process zone (i.e. or plastic zone) should be fully embedded within the region over which the singularity dominates the stress field. Qian and Akisanya [7] reported the tensile strength prediction of scarf joints subjected to a combination of mechanical and thermal loading by $H_{c}$ fracture criterion with a good accuracy. This study led to a better understanding of failure mechanisms and influences of joint geometry and cure temperature.

Most recently, Mintzas and Nowell have applied $H_{c}$ fracture criterion for predicting the strength of adhesively bonded butt, scarf and double lap joints [8]. To predict the strength of these joints, they employed asymptotic stress analysis combined with a path independent contour integral method. They reported that the predicted joint strengths are comparable to those experimental results found in the literatures. The conditions under which this $H_{c}$ fracture criterion is valid are also discussed.

With the progress of fracture mechanics methodology, many researchers have analysed the strain energy release rate (SERR) or stress intensity factor (SIF) to predict the strength and growth of a cracked adhesive joint. This approach is actually a complementary approach to that of stress magnitude and distribution analysis. However, the stress intensity factor of adhesive joint is not easily determinable when the crack grows at or near to an interface because it exhibits oscillatory singularity behaviour so it has indefinite value. Thus, many studies dealing with adhesive joints 
tends to use SERR instead of SIF [9]. It was reported that the $G_{c}$ (i.e. critical SERR) can be employed as a mixed mode fracture criterion [10]. There are many techniques available that can be used to determine the SERR in finite element (FE) analysis, e.g. J integral, virtual crack closure, virtual crack extension and stiffness derivative. Rice's $J$ integral which is the most popular has been widely used to predict the strength of adhesive joints having a crack with fairly good results $[9,11]$.

Reliability analysis is crucially required in engineering safety design, especially in the strength prediction of brittle materials; ceramic components, rock, timber, etc. Based on recent interest in this similar study, Weibull statistics based probability approach receives increasing attention and appears to be the most widely used in practice. More recently, Weibull strength distribution approach has been proven by some researchers to be the most promising failure criterion and also as an effective reliability indicator for joints bonded with brittle adhesive [12-14]. Even so, rather less work has been undertaken to facilitate the design of adhesive joints. Some investigations are briefly reviewed below.

Seo and Lim [12] have investigated experimentally the values of tensile, four-point bending and shear strength using thermosetting epoxy resin based adhesively bonded butt joints. They reported in their study, the effects of adhesive sectional area (i.e. $2 \times 3,3 \times 4,4 \times 5$ and $5 \times 6 \mathrm{~mm}^{2}$ ) and compared the above mentioned test methods in terms of joint strength, standard deviation and Weibull modulus, $m$. It was observed that strength for tensile and four-point bending specimens decreases with increasing adhesive sectional area. They concluded that specimen with adhesive sectional area of $5 \times 6 \mathrm{~mm}^{2}$ has the highest strength probability in the tensile and shear tests, while 
in the four-point bending test is $3 \times 4 \mathrm{~mm}^{2}$. Besides, shear specimen is least affected by the adhesive sectional area if compared to other test methods and yet has similar strength probability to those in the tensile specimens.

Arenas et al. [13] proposed the use of a statistical analysis based on Weibull distribution to define an optimum bond thickness that combines the best mechanical performance (i.e. shear tensile strength) with high reliability. In their experimental study, they applied acrylic adhesive to manufacture the single lap joint with 6160 aluminium alloy adherend. As a result, the optimum bond thickness for their single lap joint was reported as $0.5 \mathrm{~mm}$.

Vallée et al. [14] have developed a probabilistic method based on Weibull statistical distribution for the strength prediction of balanced adhesively bonded double lap joints composed of pultruded GFRP adherends. They also presented a short review regarding the size effects on strength of materials and FRP composites.

Hadj-Ahmed et al. [3] proposed a strength probability law to predict the shear strength of a double lap adhesive joint through analytical and numerical investigations. They related the influence of both bond thickness and overlap length upon joint strength to the Weibull modulus, $m$. The adhesive behaviour varies in accordance to the $m$ value (i.e. $m \leq 3.2$; low, $3.2 \leq m \leq 5$; intermediate or $m \geq 5$; high dispersion). They pointed out that optimal bond thickness becomes more pronounced particularly when $m$ is in intermediate dispersion (i.e. relatively ductile) model. The existence of an optimal bond thickness can be attributed to competition between "number of defects" and stress concentration effects. In the case of overlap length, they have reported that 
dispersion character of adhesive does not influence the dependence of joint strength on the overlap length, and adhesive joint displays nearly same "limit overlap length".

Burrow et al. [15] used Weibull analysis to determine the reliability of data from bond strengths to dentin measurements as well as tensile tests on resin-based dental restorative materials.

With the help of Weibull analysis, they have: (i) determined whether or not the test method has a significant effect on bond test results, (ii) obtained the information related to the overall performance of an adhesive material, and (iii) theoretically modelled the behaviour of materials systems in dental restorations.

In this paper, the authors are concerned with the prediction of mechanical performance and failure characteristics of adhesive joints of dissimilar adherends bonded with relatively brittle adhesive. The authors have also employed the reliability analysis of strength of these joints based upon the statistical Weibull analysis of strength distribution. The effects of stress singularity at the interface corner and scale sensitivity upon strength and failure of brittle adhesive joints will be discussed.

\section{Stress singularity based strength prediction}

\section{1. $H_{c}$ parameter}

Most recently, much attention has been paid to the validation of interface corner failure criterion. Consider an adhesive joint body within linear elasticity context behaviour. When the body 
is subjected to a remote uniaxial load, the asymptotic stress field develops at the vicinity of interface corners and exhibits singularity behaviour in the form of [16]:

$$
\sigma \approx H r^{-\lambda}
$$

where $\sigma$ is the stress, $r$ is distance from the interface corner, $H$ is intensity of stress singularity and $\lambda$ is order of stress singularity. The $H$ failure criterion has been originally proposed by Groth [17] and is analogous to the linear elastic fracture mechanics (LEFM) concept, where it is associated with the discontinuity at the interface corner instead of crack. Failure is assumed to initiate at the interface corner when $H$ exceeds the critical value, $H_{c}$.

In order for $H_{c}$ to be a valid failure criterion, any plasticity (i.e. non-linear deformation or failure process zone) must be confined to a small singularity region at the interface corner: condition referred to as small scale yielding theory in LEFM. There are already some experimental evidences, which emphasized that $H_{c}$ and $\lambda$ parameters can be effectively used to successfully predict the onset of failure and eventually evaluate the relationship between bond thickness and adherend stiffness, and the strength of certain adhesively-bonded butt and scarf joints [4, 18, 19]. Hence, the evaluation of $\lambda$ in such adhesive joints is of technical importance, and this can be fulfilled via adopting the calculation method as performed by Bogy [20]. In this study, the calculation of $\lambda$ at an interface corner of a bi-material joint was carried out analytically by using Fortran PowerStation 4.0 software (i.e. see Appendixes A). The results will be discussed in the following section. 


\section{2. $J_{c}$ parameter}

$H_{c}$ parameter which has been explained in the previous subsection is suitable to the problem of adhesive joint without defect. However, for adhesive joint with intrinsic or artificial interfacial crack the application of fracture toughness, $J c$ parameter as a fracture is seemed to be appropriate. This fracture criterion parameter has the non-dimensional form of a combination of parameters as follows [21, 22]:

$$
\phi^{2}\left[\frac{a}{t}\right]=\frac{\bar{E}_{a d h} J c}{\sigma_{c}^{2} t}
$$

where $\Phi$ is a function to be determined, $a$ is the crack length, $t$ is bond thickness and $\bar{E}_{a d h}=E_{a d h} /\left(1-v_{c}^{2}\right)$ is the plane strain Young's modulus of adhesive layer. Therefore, if one knows the fracture toughness of a particular adhesive joint which is independent of $t$, one may predict critical fracture stress, $\sigma_{c}$ of the said adhesive joint. The critical fracture stress of adhesive joint with a defect can be derived as:

$$
\sigma_{c}=\sqrt{\frac{-E_{a d h} J c}{\phi^{2} t}}
$$

Fracture toughness can be evaluated by $\mathrm{J}$ integral calculation in FE analysis. For a nonlinear elastic body containing a crack in $2 \mathrm{D}$ problem, the $\mathrm{J}$ integral is given by [11]:

$$
J=\int_{\Gamma}\left(W d y-T_{i} \frac{\partial u_{i}}{\partial x} d s\right)
$$


where $u_{i}$ is the displacement vector components and $d s$ is the length increment along an arbitrary counterclockwise contour $\Gamma$ around the crack-tip. The strain energy density is defined by

$$
W=W\left(\varepsilon_{i j}\right)=\int_{0}^{\varepsilon_{i j}} \sigma_{i j} d \varepsilon_{i j}
$$

where $\sigma_{i j}$ and $\varepsilon_{i j}$ are the stress and strain tensors, respectively. The components of traction vector are given by

$$
T_{i}=\sigma_{i j} n_{j}
$$

where $n_{j}$ is the components of the unit vector normal to $\Gamma$.

To evaluate $\mathbf{J}$ integral of FE model, series of ANSYS commands for $\mathbf{J}$ contour integration formulation were saved in a macro file. After FE analysis solution was converged, a set of circular contours around the crack-tip was defined. The radius of contours was defined as $0.25 a, 0.5 a, 0.75 a$ and $a$, where $a$ is the crack length. The macro file was then executed at each pre-determined circular contour and the corresponding $\mathbf{J}$ value has been recorded. Thus, $\mathbf{J}$ was taken as an average value from a set of $\mathbf{J}$ values obtained at each execution. Refer to Appendix B for macro of $\mathbf{J}$ integral in ANSYS. Calibration of $\mathrm{J}$ value is needed beforehand because the actual bond thickness in a specimen might be varied from the targeted value.

\section{Weibull statistical strength distribution}

When the failure of material is sensitive to the nature and distribution of flaws or defects within the specimens, this material strength will exhibit a scale sensitivity or size effect. This size effect is indeed based on weakest link theory and thus the severity level of defects will determine 
the variability of failure load. The larger the specimen is, the higher the severity level is and the lower the strength of corresponding sample will be. The size effect on the material strength is adequately explained by statistical probability theories such as Weibull strength distribution theory. Two types of Weibull statistical distribution are available: two-parameter and three-paramater. Due to its simplicity, in this study, the authors have chosen two-parameter Weibull distribution (i.e. shape and scale parameters) to represent the strength probabilities of adhesive joint. As originally proposed by Weibull [23], the cumulative probability of failure, $P_{f}$ in the simplified form can be expressed by:

$$
P_{f}=1-\exp \left[-\left(\frac{\sigma}{\sigma_{0}}\right)^{m}\right]
$$

where, $m$ and $\sigma_{0}$ are shape and scale parameters, respectively. $m$ is conveniently referred to as the Weibull modulus. These two parameters can be determined by several means; however, the linear regression method is more straightforward. Furthermore, if one takes double natural logarithms for Eq. (4), one may consider another empirical equation:

$$
Y=\ln \ln \left[\frac{1}{1-P_{f}}\right]=m \ln \sigma-m \ln \sigma_{0}
$$

Thus, $m$ can be readily obtained directly from the slope of plot $Y$ against $\ln \sigma$. The $P_{f}$ can be calculated by experimentally testing a number $(n)$ of specimens, and then ranking the measured strengths in ascending order [12]. In the literature, $P_{f}$ is often defined by using several estimators [24] and the most established to be used is the following equation $[12,15,25]$ :

$$
P_{f-1}=\frac{i}{n+1}
$$


in which $i$ is the ranking of the failure stress and $n$ is total number of tested specimens.

\section{Experimental procedures}

Epoxy adhesive resin used in this study was Hi-Super 30 produced by Cemedine Co., Japan.

General information regarding material properties of this adhesive are tabulated in Table 1 . The adhesive was prepared prior to bonding by mixing thoroughly epoxy resin and hardener inside a 12 $\mathrm{ml}$ ointment container at 1:1 ratio (i.e. 3.5 gram each) using a centrifugal conditioning mixer. Schedule of diffusion and de-foaming were $1 \mathrm{~min}$ and $3 \mathrm{~min}$, respectively. Cure state was at room temperature (R.T.) for over 24 hours. Adherends were consisted of SUS304 stainless steel and YH75 aluminium alloy. Mechanical properties of adhesive and adherends are given in Table 2.

To investigate strength and failure behaviour of adhesive joints, butt, scarf and shear joint specimens were prepared and its configuration and dimensions are shown in Fig. 1. Prior to bonding, bonding surfaces were uniformly polished with \# 2000 waterproof abrasive paper and afterward degreased with acetone. Adhesive bond thickness, $t$ inside a specimen was controlled by using a specially developed fixture and varied between $0.1 \mathrm{~mm}$ and $1.2 \mathrm{~mm}$ (i.e. Series A). For Series A, three specimens were prepared at each bond thickness. Other 10 specimens having only $0.1 \mathrm{~mm}$ bond thickness were also prepared (i.e. Series B). After specimens were totally cured, the excessive adhesive was carefully removed by a portable grinder and curving knife. Then, actual bond thickness of each specimen was measured by a digital microscope. 
For specimens with interfacial crack, an interfacial crack which originated from an interface corner was inserted to represent a straight flaw at adhesive joints interface. This pre-crack was introduced by pasting a strip of $0.05 \mathrm{~mm}$ thick Teflon tape on the edge of adherend surface prior to bonding. Ratio $a / W$ is constant at $1 / 8$, where $a$ is interface pre-crack length and $W$ is the specimen width.

Failure tensile tests of adhesive joint specimens were carried out by a universal testing machine (INSTRON 4206). All specimens were tested at R.T. with the crosshead speed held constant at $0.5 \mathrm{~mm} / \mathrm{min}$.

\section{Results and discussion}

\subsection{Strength and failure prediction}

\subsubsection{Non-cracked adhesive joint}

Fig. 2 shows the load versus crosshead displacement of various adhesive joints tested under tension or shear force in this study. This figure only shows the representative results obtained from adhesive joint specimens having (a) $0.1 \mathrm{~mm}$, and (b) $1.0 \mathrm{~mm}$ bond thickness (i.e. part of Series A). It is noted that the failure load of scarf joints specimen decreases with increasing scarf angle. Shear joint specimen shows the lowest failure load. In all specimens, load increases gradually with displacement until sudden failure occurs. Very similar trends have also been found on other specimens having bond thickness between $0.1 \mathrm{~mm}$ and $1.2 \mathrm{~mm}$. 
Failure paths of adhesive joints are now illustrated schematically in Fig. 3. For butt joints, failure initiates at the SUS304/epoxy interface corner, A, and then immediately deviates into the adhesive layer and propagates inside it until complete separation. Thus, the final appearance of surface was almost cohesive failure. Meanwhile, for scarf joints, even the failure still onset at an identical spot (i.e. A), the distance where it starts deviating into the adhesive layer is slightly different for different scarf angle. The failure ends at the opposite ALYH75/epoxy interface corner, A'. However, there is no obvious discrepancy in terms of joint strength between path A and path B. Intrinsic properties of adhesion might play a major role to this phenomenon $[1,26]$. In the case of shear joints, the failure begins at the ALYH75/epoxy interface corner, B. The separation occurs completely at the ALYH75 interface. In shear joints tested it is found that the interface failure is dominant.

The above-mentioned observations can be best explained in terms of stress singularity order, $\lambda$ at the interface corners of adhesive joint. There are four interface corners where stress singularity exists, i.e. A, A', B and B', as illustrated diagrammatically in Fig. 3. Following the same procedure as Bogy as mentioned above, assuming the plane strain condition, $\lambda$ of adhesive joints under consideration has been evaluated. The results for butt and scarf adhesive joints are first plotted in Fig. 4. As can be seen, $\lambda$ at an interface corner varies with the scarf angle and vanishes at a certain scarf angle. From these results, at a glance, one can anticipate at which interface corner the adhesive joint will fail. For example, at $45^{\circ}$ scarf angle, $\lambda$ exists at SUS304/epoxy interface corner but not at ALYH75/epoxy interface corner. So, in this case, it can be predicted that the failure will always 
initiate at SUS304/epoxy interface corner. One results shows $\lambda$ exists at both interface corners, let say in $75^{\circ}$ scarf joints. In this case, $\lambda$ at the SUS304/epoxy interface corner A and ALYH75/epoxy interface corner B was measured as 0.3648 and 0.3069 , respectively. Since the order of stress singularity at the former is higher than the latter, the failure is predicted to initiate at the former.

Stress singularity at interface corners of adhesive joints (i.e. A, B, A' and B') which has been obtained from our analytical calculations are now summarized in Table 3 below. From this table, one may notice that the order of singularity at the SUS304/epoxy interface corner, A is always higher if compared to other interface corners in butt and scarf joints. In fact, it has been confirmed from the failure surface observations that failure initiates at $\mathrm{A}$ in almost all specimens tested. However, the highest order of singularity in shear joints is at the ALYH75/epoxy interface corner, B with the value of 0.3623 . For shear joints, failure initiated at B as can be appreciated from failure surface observation. Obviously, this feature provides a fairly good explanation why the failure in butt and scarf joints does initiate from A, while in shear joint is always at B.

It is essential to determine the critical failure stress of adhesive joints. The relation between the critical failure (or shear) stress and bond thickness which has been obtained from our experimental study is depicted in Fig. 5. It is obvious from this figure that the critical stresses reduce gradually with increasing bond thickness in all types of specimens. This indicates a typical influence of bond thickness upon the strength of brittle adhesive joints and similar pattern has been reported elsewhere $[1,4,6,14]$. 
To predict the strength of adhesive joints and its relation to bond thickness, the interface corner toughness, $H_{c}$ approach is now applied. The value of interface corner toughness, $H_{c}$ characterises the magnitude of stress state in the region of sharp interface corner. The calibration relation defining $H_{c}$ can be determined by fitting asymptotic and full-field finite element solution (i.e. extrapolation method and contour integral method), and it depends on applied loading, joint geometry, and bi-material elastic properties. According to Akisanya and Meng [5], $H_{c}$ is defined by:

$$
H_{c}=\sigma_{c} t^{\lambda} Q(\alpha, \beta)
$$

where $Q$ is a non-dimensional constant function of the material elastic parameters (i.e. Dundurs' parameters). Since adherends are much more rigid than epoxy adhesive, $\alpha=0.99$ and $\beta=\alpha / 4$ are considered. For these materials combinations, value of $Q$ is tabulated in Table 4, based on solution for sandwiched scarf joint published in [6], and [27] for shear joint. For shear joint, $\sigma_{c}$ in Eq. (7) is readily substituted with critical shear stress, $\tau_{c}$. The values of $\lambda_{\max }$ and average values of $H_{c}$ (i.e. $\hat{H}_{c}$ ) as well as standard deviation for 10 specimens having $0.1 \mathrm{~mm}$ bond thickness tested (i.e. Series B) are summarized in Table 4 . Here, $\lambda_{\max }$ is referred to the highest value of $\lambda$ amongst four interface corners. $\hat{H}_{c}$ is the average value of $H_{c}$ obtained from 10 similar type of adhesive joint having 0.1 mm bond thickness. It is noted that the ratio of standard deviation to $\hat{H}_{c}$ is less than $35 \%$. This result supports that $H_{c}$ is a suitable failure criterion which depends only on joint geometry and material properties. By using the value of $\hat{H}_{c}$ in conjunction with Eq. (7), inversely, the strength for each adhesive joint in Series A can be predicted. Prediction lines for strength of adhesive joints having $0^{\circ}, 45^{\circ}, 60^{\circ}, 75^{\circ}$ and $90^{\circ}$ are represented by long dash line, short dash line, dash-dot line and 
dot-dot line, respectively, as shown in Fig. 5. Obviously, to some extent, the prediction is in good agreement with the measured data. Hence, it is concluded that the application of $H_{c}$ approach is appropriate for estimation of strength of non-cracked brittle epoxy adhesively bonded joints.

\subsubsection{Adhesive joint with an interfacial crack}

From fracture surface observation, fracture of specimens with an interfacial crack fell mainly into two categories, i.e. cohesive fracture and interface fracture. First, the joint strength prediction based on $J_{c}$ parameter is carried out for specimens that fractured with cohesive characterisations. In order to achieve this, Eqs. (2) and (3) above are employed. Here, fracture toughness, $J_{c}$ is evaluated using $\mathrm{J}$ integral calibration in FE as discussed in Section 2.2 above. Since, $\mathrm{J}$ integral calibration was conducted with the applied stress of $1 \mathrm{MPa}, J_{c}$ is obtained by multiplying critical fracture stress, $\sigma_{c}$ to the pre-calibrated $\mathrm{J}$ value.

Fig. 6 shows the fracture stress against bond thickness for butt joint with an interfacial crack. Here, SEA and AES represent the joint specimens with an interfacial crack at SUS304/adhesive interface and ALYH75/adhesive interface, respectively. For both SEA and AES systems, the prediction lines fit well with the corresponding experimental data. Almost same validation and tendency can be appreciated from the results of scarf joints with an interfacial crack as shown in Fig.

7 (a) and (b). If $J_{c}$ for an adhesive joint is constant, the strength of this system will be depended on bond thickness; fracture stress decreases when the bond thickness increases. 
In other cases, adhesive joint failed entirely at ALYH75/epoxy interface. Therefore, in these specimens, another fracture criterion will be invoked. It is assumed that the interfacial crack behaves similarly to a centre crack in adhesive layer constrained between two rigid substrates. By doing so, the interfacial toughness, $K_{c}$ can be in the simplest way expressed as follows:

$$
K_{c} \cong \sigma_{c} \sqrt{\pi a} \cdot F(a / W) \cong \sigma_{c} \sqrt{t / 2}
$$

As in the case of $J c$ parameter, in order to be a valid fracture criterion, $K_{c}$ parameter needs to be a constant. Fig. 8 and Fig. 9 show the prediction of fracture stress against bond thickness based on $K_{c}$ parameter in butt joint and shear joint, respectively. It is seen that in both cases, the prediction lines are in good correlation with the experimental results, henceforth verified the applicability of $K_{c}$ parameter as fracture criterion for adhesive joints which failed $100 \%$ at interface.

\subsection{Reliability of adhesive joint}

As discussed in Section 5.1.1 above, failure stress of non-cracked adhesive joints shows some uncertainty. Therefore, it is of practical interest to analyse the strength reliability of adhesive joints considered under this study. First, as a pilot work, Weibull strength analysis of shear joint with four different bond thickness (i.e. $0.1 \mathrm{~mm}, 0.3 \mathrm{~mm}, 0.7 \mathrm{~mm}$ and $1.0 \mathrm{~mm}$ ) was conducted. For each condition, 10 specimens were tested. Fig. 10 shows the results which have been obtained. It is obvious from Fig. 10 (a) that there is a considerably large scatter in the measured failure shear stress. Fig. 10 (b) shows Weibull plots of shear joints. It is noted that in this investigation, Eq. was used to evaluate the probability of failure, $P_{f}$. In actual practice, 10 specimens may be 
insufficient to draw a solid conclusion $[14,28]$. However, with only 10 specimens for each configuration, a good linear regression was already obtained as can be appreciated from Fig. 10 (b). This suggests that the present result has some useful validity. Fig. 10 (c) gives a direct comparison on the correlation between Weibull modulus, $m$ as well as average failure stress against bond thickness. It is noted that both $m$ and average failure stress decrease with increasing bond thickness, i.e. shear joint with thin adhesive layer (i.e. $0.1 \mathrm{~mm}$ ) has high strength performance and high reliability. Hence, for reliability analysis of butt and scarf joints, 10 specimens having only $0.1 \mathrm{~mm}$ bond thickness were also evaluated (i.e. Series B).

Fig. 11 shows the logarithmic Weibull plots of various adhesive joint specimens for Series $\mathrm{A}$ and $\mathrm{B}$. Note that Series A data include all specimens having bond thickness ranged from $0.1 \mathrm{~mm}$ to $1.0 \mathrm{~mm}$. These results are now summarized in Fig. 12. It appears that both Series A and Series B show a similar pattern except values in Series A are lower than those in Series B. With increasing scarf angle, $m$ is gradually reduced, but then, increases again before eventually declines further. As a conclusion, shear joints have the highest strength reliability than others. From both results of Series A and B, the failure probability in descending order is butt joint (i.e. $90^{\circ}$ ), $60^{\circ}$ scarf joints, $45^{\circ}$ scarf joints, $75^{\circ}$ scarf joints and shear joints (i.e. $0^{\circ}$ ).

The reason why the value of $m$ decreases with the increase in scarf angle, $\theta$ is likely to be associated with changes in the failure surface morphology. For $\theta=0^{\circ}$ (i.e. shear joint), only interface failure was observed, but when $\theta$ increases the ratio of cohesive fracture also increases, especially for $\theta=45^{\circ}, 60^{\circ}$ and $90^{\circ}$. In the scarf joint (i.e. $\theta=45^{\circ}$ and $60^{\circ}$ ), cohesive failure can be 
clearly seen because of failure meanders from an interface to the opposite interface. Moreover, in the butt joint (i.e. $\theta=90^{\circ}$ ), cohesive failure is dominant and the interface fracture occurs only in a small area at the interface corner neighbourhood.

On the other hand, it is noted that the cohesive failure ratio also increases with increasing thickness of the adhesive. It is observed that there is tendency where data scattering is become worst when the failure in specimen is governed by cohesive failure. Therefore, this is the best explanation of why the value of $m$ for the Series A is lower than those in Series B. Based upon the present experimental results, it appears that $45^{\circ}$ scarf joints have the best failure stress performance with tolerably good $m$ value. Therefore, it can be concluded that $45^{\circ}$ scarf joints should be considered when designing adhesive joints with the same adhesive as used in this study. It should be noted that, $H_{c}$ and $m$ are a specimen property. Hence, the application of both parameters is highly recommended for better prediction of strength and reliability determination of non-cracked brittle adhesive joints. The application of reliability analysis of fracture stress for specimen with interfacial crack is yet to be addressed. 


\section{Conclusions}

The strength and failure prediction as well as the reliability issues of adhesive joints of brittle epoxy bonding two dissimilar adherends have been addressed. As a result, strength of adhesive joint reduces with increasing bond thickness and scarf angle. The failure initiated at a location with the highest stress singularity order which is the interface corner of SUS304/epoxy of butt and scarf joints. However, the failure initiation site of shear joints is at the ALYH75/epoxy interface. Strength prediction of various non-cracked adhesive joints can be done by interface corner toughness, $H_{c}$ parameter. For adhesive joints with an interfacial crack, strength prediction can be obtained using $J_{c}$ or $K_{c}$ depends on the type of failure observed in specimens. Moreover, shear joint specimens have higher reliability than butt and scarf joints, although the stress singularity order at interface corner is maximal. Besides, scarf joint of $45^{\circ}$ has relatively lower stress singularity and Weibull modulus is moderate. Hence, it can be concluded that the scarf joint of $45^{\circ}$ is preferable since it satisfies both outstanding load-bearing performance and tolerable reliability. Finally, with both applications of $H_{c}$ parameter and Weibull statistical method, strength prediction of non-cracked adhesive joints can be achieved and their reliability can be determined. 


\section{References}

[1] Kinloch AJ. Adhesion and Adhesives: Science and Technology. London: Chapman and Hall; 1987.

[2] Wang CH. Fracture of interface cracks under combined loading. Engineering Fracture Mechanics. 1997;56:77-86.

[3] Hadj-Ahmed R. Probabilistic analysis of failure in adhesive bonded joints. Mechanics of Materials. 2001;33:77-84.

[4] Reedy ED, Guess TR. Interface corner failure analysis of joint strength: effect of adherend stiffness. International Journal of Fracture. 1997;88:305-14.

[5] Reedy E. Connection between interface corner and interfacial fracture analyses of an adhesively-bonded butt joint. International Journal of Solids and Structures. 2000;37:2429-42.

[6] Akisanya AR, Meng CS. Initiation of fracture at the interface corner of bi-material joints. Journal of the Mechanics and Physics of Solids. 2003;51:27-46.

[7] Qian Z, Akisanya AR. An experimental investigation of failure initiation in bonded joints. Acta Metallugica. 1998;46:4895-904.

[8] Mintzas A, Nowell D, Validation of an $\mathrm{H}_{\mathrm{cr}}$-based fracture initiation criterion for adhesively bonded joints. Engineering Fracture Mechanics 2012;80:13-27.

[9] Chen Z, Adams RD, da Silva LFM. The use of the J-integral vector to analyse adhesive bonds with and without a crack. International Journal of Adhesion and Adhesives. 2011;31:48-55. 
[10] Zhu Y. Stress analysis and failure prediction for adhesively bonded joints. Santa Barbara:

University of California; 2006.

[11] Rice JR. A path independent integral and the approximate analysis of strain concentration by notches and cracks. Journal of Applied Mechanics. 1968;35:379-86.

[12] Seo D, Lim J. Tensile, bending and shear strength distributions of adhesive-bonded butt joint specimens. Composites Science and Technology. 2005;65:1421-7.

[13] Arenas JM, Narbón JJ, Alía C. Optimum adhesive thickness in structural adhesives joints using statistical techniques based on Weibull distribution. International Journal of Adhesion and Adhesives. 2010;30:160-5.

[14] Vallee T, Correia J, Keller T. Probabilistic strength prediction for double lap joints composed of pultruded GFRP profiles - Part II: Strength prediction. Composites Science and Technology. 2006;66:1915-30.

[15] Burrow MF, Thomas D, Swain MV, Tyas MJ. Analysis of tensile bond strengths using Weibull statistics. Biomaterials. 2004;25:5031-5.

[16] Dillard DA. The Mechanics of Adhesion. Amsterdam: Elsevier Science B. V.; 2002.

[17] Groth HL. Prediction of failure loads of adhesive joints using the singular intensity factors. Fracture Mechanics: Eighteenth Symposium: ASTM STP 945; 1988. p. 278-84.

[18] Qian ZQ, Akisanya AR. An investigation of the stress singularity near the free edge of scarf joints. Euro J Mech. 1999; 18:443-63. 
[19] Reedy Jr ED, Guess TR. Interface corner stress states: plasticity effects. International Journal of Fracture. 1996;81:269-82.

[20] Bogy DB. Two edge-bonded elastic wedges on different materials and wedge angles under surface tractions. Transactions of ASME, Journal of Applied Mechanics. 1971;38:377-86.

[21] He MY, Evans AG, Yehle A. Criterion for the avoidance of edge cracking in layered systems. Journal of the American Ceramic Society. 2008;1423:1418-23.

[22] Hutchinson JW, Suo Z. Mixed mode cracking in layered materials. In: Hutchinson JW, Wu TY, editors. California: Academic Press, Inc.; 1992. p. 63-191.

[23] Weibull W. A statistical distribution function of wide application. Journal of Applied Mechanics. 1951;18:287-93.

[24] Saghafi A, Mirhabibi AR, Yari GH. Improved linear regression method for estimating Weibull parameters. Theoretical and Applied Fracture Mechanics. 2009;52:180-2.

[25] Fok S. A numerical study on the application of the Weibull theory to brittle materials.

Engineering Fracture Mechanics. 2001;68:1171-9.

[26] Ebnesajjad S. Adhesive Technology Handbook. 2 ed. New York: William Andrew Inc.; 2008.

[27] Wang CH, Rose LRF. Compact solutions for the corner singularity in bonded lap joints.

International Journal of Adhesion and Adhesives. 2000;20:145-154.

[28] McCabe JF, Carrick TE. A statistical approach to the mechanical testing of dental materials.

Dental Materials. 1986;2:139-42. 


\section{Appendix A}

Bogy's singularity evaluation in Fortran PowerStation 4.0

C......SINGULAR.FOR

IMPLICIT REAL*8(A-H,O-Z)

ESUS $=206000$

$\mathrm{EAL}=71000$

$\mathrm{EADH}=3400$

PNUSUS $=0.3$

PNUAL $=0.33$

PNUADH $=0.396$

$\mathrm{EPS}=1 . \mathrm{D}-5$

C.... GS $=0.5^{*} \mathrm{ESUS} /(1.0+\mathrm{PNUSUS})$

C.... GA $=0.5 * \mathrm{EAL} /(1.0+\mathrm{PNUAL})$

C.... GAD $=0.5 * \mathrm{EADH} /(1.0+\mathrm{PNUADH})$

WRITE(6,*) 'PLANE STRESS=0, PLANE STRAIN=1..'

$\operatorname{READ}(5, *) \operatorname{IPP}$

WRITE(6,*) 'SUS=0, AL=1..'

$\operatorname{READ}\left(5,{ }^{*}\right)$ IYOUNG

IF(IYOUNG.EQ.0) THEN

$\mathrm{E} 1=\mathrm{ESUS}$

PNU1=PNUSUS

ELSE

$\mathrm{E} 1=\mathrm{EAL}$

PNU1=PNUAL

ENDIF

C.

$\mathrm{E} 2=\mathrm{EADH}$

PNU2=PNUADH

CALL PLANE(IPP,E1,PNU1,RK1,G1)

CALL PLANE(IPP,E2,PNU2,RK2,G2)

$\mathrm{BUNBO}=\mathrm{G} 1 *(\mathrm{RK} 2+1.0)+\mathrm{G} 2 *(\mathrm{RK} 1+1.0)$

$\mathrm{ALF}=(\mathrm{G} 1 *(\mathrm{RK} 2+1.0)-\mathrm{G} 2 *(\mathrm{RK} 1+1.0)) / \mathrm{BUNBO}$

$\mathrm{BET}=(\mathrm{G} 1 *(\mathrm{RK} 2-1.0)-\mathrm{G} 2 *(\mathrm{RK} 1-1.0)) / \mathrm{BUNBO}$

WRITE(6,*)'ALF,BET...',ALF,BET

C

$\mathrm{PI}=3.141592653589793$

$\mathrm{T} 1=\mathrm{PI} / 2$

$\mathrm{T} 2=\mathrm{PI} / 2$

C $\quad \mathrm{T} 2=\mathrm{PI}$ 


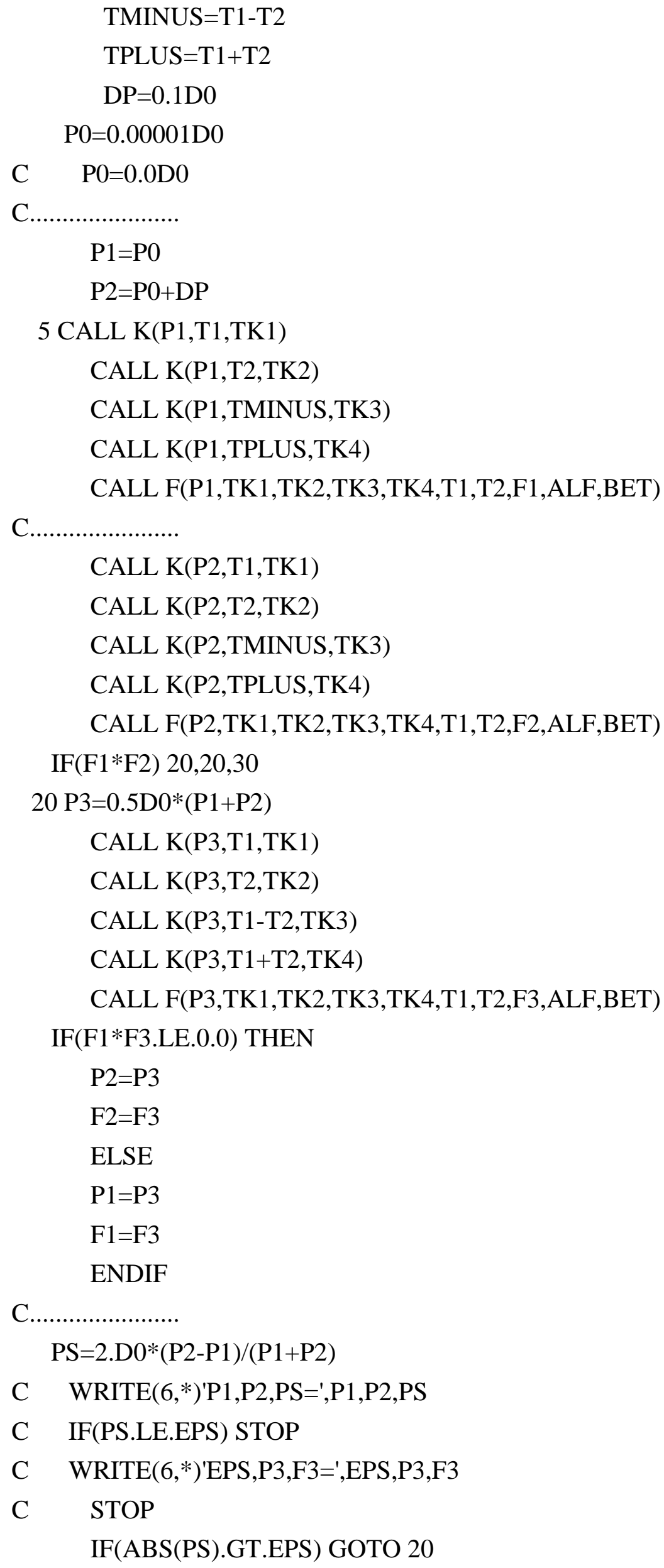




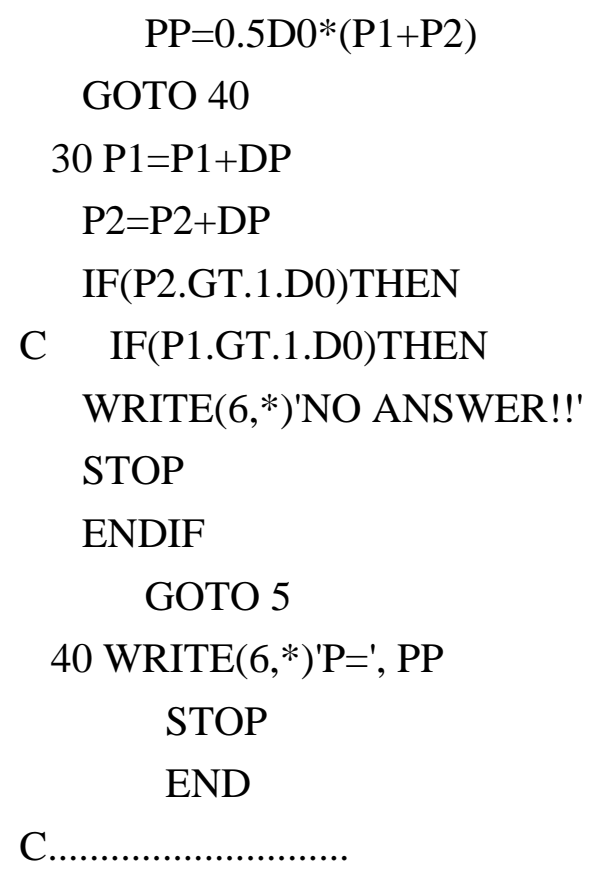

SUBROUTINE PLANE(IPP,E,PNU,RK,G)

IMPLICIT REAL*8(A-H,O-Z)

IF(IPP.EQ.0) THEN

$\mathrm{RK}=(3.0-\mathrm{PNU}) /(1.0+\mathrm{PNU})$

ELSE

$\mathrm{RK}=3.0-4.0 * \mathrm{PNU}$

ENDIF

$\mathrm{G}=0.5^{*} \mathrm{E} /(1.0+\mathrm{PNU})$

RETURN

END

C.

SUBROUTINE K(P,T,TK)

IMPLICIT REAL*8(A-H,O-Z)

$\mathrm{S} 1=\mathrm{SIN}\left(\mathrm{P}^{*} \mathrm{~T}\right)$

$\mathrm{S} 2=\mathrm{SIN}(\mathrm{T})$

$\mathrm{TK}=\mathrm{S} 1 * \mathrm{~S} 1-\mathrm{P} * \mathrm{P} * \mathrm{~S} 2 * \mathrm{~S} 2$

RETURN

END

C.

SUBROUTINE F(P,TK1,TK2,TK3,TK4,T1,T2,FX,ALF,BET)

IMPLICIT REAL*8(A-H,O-Z)

$\mathrm{A}=4.0 * \mathrm{TK} 1 * \mathrm{TK} 2$

$\mathrm{B}=2.0 * \mathrm{P} * \mathrm{P} *(\mathrm{SIN}(\mathrm{T} 1) * \mathrm{SIN}(\mathrm{T} 1) * \mathrm{TK} 2+\mathrm{SIN}(\mathrm{T} 2) * \mathrm{SIN}(\mathrm{T} 2) * \mathrm{TK} 1)$

$\mathrm{C} 1=\mathrm{SIN}(\mathrm{T} 1) * \operatorname{SIN}(\mathrm{T} 2)$

$\mathrm{C}=4.0 * \mathrm{P} * \mathrm{P} *(\mathrm{P} * \mathrm{P}-1.0) * \mathrm{C} 1 * \mathrm{C} 1+\mathrm{TK} 3$

$\mathrm{D} 1=\mathrm{SIN}(\mathrm{T} 1) * \mathrm{SIN}(\mathrm{P} * \mathrm{~T} 2)$ 
$\mathrm{D} 2=\mathrm{SIN}(\mathrm{T} 2) * \mathrm{SIN}(\mathrm{P} * \mathrm{~T} 1)$

$\mathrm{D}=2.0 * \mathrm{P} * \mathrm{P} *(\mathrm{D} 1 * \mathrm{D} 1-\mathrm{D} 2 * \mathrm{D} 2)$

$\mathrm{E}=-\mathrm{D}+\mathrm{TK} 2-\mathrm{TK} 1$

$\mathrm{FF}=\mathrm{TK} 4$

$\mathrm{FX}=\mathrm{A} * \mathrm{BET} * \mathrm{BET}+2.0 * \mathrm{~B} * \mathrm{ALF} * \mathrm{BET}+\mathrm{C} * \mathrm{ALF} * \mathrm{ALF}-2.0 * \mathrm{D} * \mathrm{BET}-2.0 * \mathrm{E}^{*} \mathrm{ALF}+\mathrm{FF}$ RETURN

END 


\section{Appendix B}

Macro of $\mathbf{J}$ integral calculation in ANSYS 11

ETABLE,SENE,SENE

ETABLE,VOLU,VOLU

SEXP,W,SENE,VOLU,1,-1 ! CALCULATE STRAIN ENERGY DENSITY

!LPATH,n1,n2, ... nn ! DEFINE PATH POINTS BY NODE

PDEF,W,ETAB,W ! PUT STRAIN ENERGY DENSITY ON THE PATH

PCALC,INTG,J1,W,YG ! INTEGRATE ENERGY W.R.T. GLOBAL Y

*GET,JA,PATH,,LAST,J1 ! GET FINAL VALUE OF INTEGRAL FOR 1ST TERM OF J

PDEF,CLEAR ! CLEAR OLD PATH VARIABLES

PVECT,NORM,NX,NY,NZ ! DEFINE THE PATH UNIT NORMAL VECTOR

PDEF,INTR,SX,SX ! PUT STRESS SX ON THE PATH

PDEF,INTR,SY,SY! PUT STRESS SY ON THE PATH

PDEF,INTR,SXY,SXY ! PUT STRESS SXY ON THE PATH

PCALC,MULT,TX,SX,NX! CALCULATE TRACTION TX

PCALC,MULT,C1,SXY,NY! TX = SX*NX + SXY*NY

PCALC,ADD,TX,TX,C1

PCALC,MULT,TY,SXY,NX! CALCULATE TRACTION TY

PCALC,MULT,C1,SY,NY ! TY = SXY*NX + SY*NY

PCALC,ADD,TY,TY,C1

*GET,DX,PATH,,LAST,S ! DEFINE PATH SHIFT AS 1\% OF PATH LENGTH

$\mathrm{DX}=\mathrm{DX} / 100$

PCALC,ADD,XG,XG,,,,-DX/2 ! SHIFT PATH FROM X TO X-DX/2 (GLOBAL X DIR.)

PDEF,INTR,UX1,UX ! DEFINE UX AT X-DX

PDEF,INTR,UY1,UY ! DEFINE UY AT X-DX

PCALC,ADD,XG,XG,,,DX ! SHIFT PATH FROM X-DX/2 TO X+DX/2

PDEF,INTR,UX2,UX ! DEFINE UX AT X+DX

PDEF,INTR,UY2,UY ! DEFINE UY AT X+DX

PCALC,ADD,XG,XG,,,,-DX/2 ! SHIFT PATH BACK TO ORIGINAL POSITION

$\mathrm{C}=(1 / \mathrm{DX})$

PCALC,ADD,C1,UX2,UX1,C,-C ! CALCULATE DERIVATIVE DUX/DX

PCALC,ADD,C2,UY2,UY1,C,-C ! CALCULATE DERIVATIVE DUY/DX

PCALC,MULT,C1,TX,C1! DEFINE INTEGRAND

PCALC,MULT,C2,TY,C2 ! = TX*DUX/DX + TY*DUY/DX

PCALC,ADD,C1,C1,C2

PCALC,INTG,J2,C1,S ! FORM SECOND INTEGRAL (W.R.T. PATH LENGTH S)

*GET,JB,PATH,,LAST,J2 ! GET FINAL VALUE OF INTEGRAL FOR 2ND TERM OF J PCALC,ADD,J3,J1,J2,,-1 
*GET,J11,PATH,,LAST,J3

!J11=JA-JB ! FOR FULL MODELS

!PDEF,CLEAR ! CLEAR PATH VARIABLES

!*END 


\section{List of Tables}

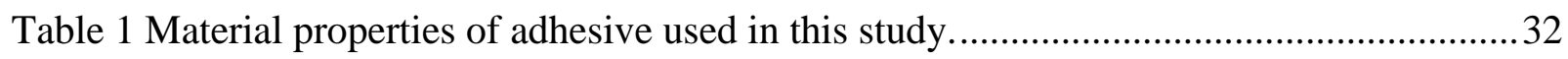

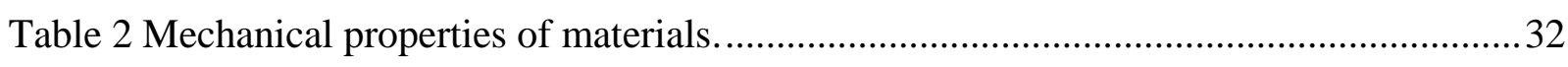

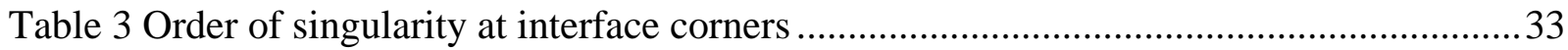

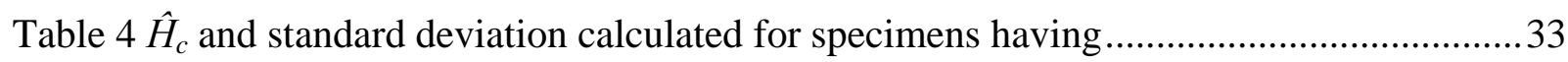




\section{List of Figures}

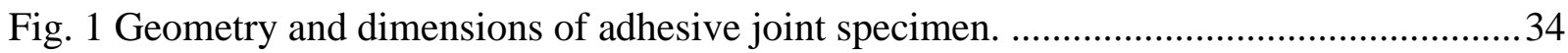

Fig. 2 Load versus displacement of various adhesive joints in tensile or shear tensile tests.... 35

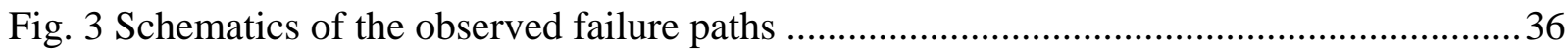

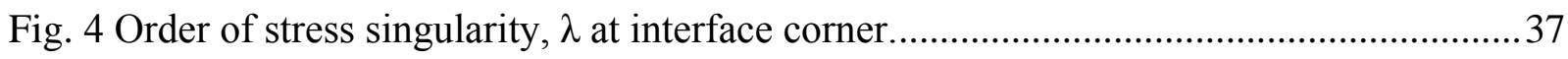

Fig. 5 Critical failure stress against bond thickness.............................................................. 37

Fig. 6 Prediction of fracture stress against bond thickness for butt adhesive joint with an

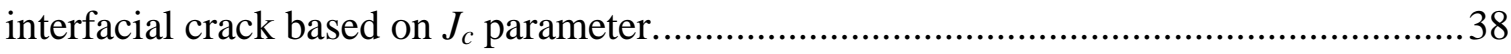

Fig. 7 Prediction of fracture stress against bond thickness for scarf adhesive joint with an interfacial crack, (a) SEA and (b) AES.

Fig. 8 Prediction of fracture stress against bond thickness in butt adhesive joint with an interfacial crack based on $K_{c}$ parameter. 40

Fig. 9 Prediction of failure stress against bond thickness in shear adhesive joint based on $K_{c}$ parameter.. 41

Fig. 10 Weibull strength analysis of shear adhesive joint. 43

Fig. 11 Logarithmic Weibull plots of adhesive joint specimens. 44

Fig. 12 Weibull modulus against various scarf angles. 45 
Table 1 Material properties of adhesive used in this study.II

\begin{tabular}{|c|c|c|}
\hline Property & \multicolumn{2}{|c|}{ High-Super30 } \\
\hline \multirow[b]{2}{*}{ Viscosity $\left(\mathrm{Pa} . \mathrm{s} / 23^{\circ} \mathrm{C}\right)$} & Epoxy & $\overline{70}$ \\
\hline & Hardener & 160 \\
\hline \multirow[b]{2}{*}{ Density $\left(\mathrm{g} / \mathrm{cm}^{3}\right)$} & Epoxy & 1.17 \\
\hline & Hardener & 1.14 \\
\hline Curing time & \multicolumn{2}{|c|}{$30 \mathrm{~min}}$. \\
\hline Mature bonding time & \multicolumn{2}{|c|}{$1 \mathrm{~h}$} \\
\hline Tensile shear strength $\left(\mathrm{N} / \mathrm{mm}^{2}\right) *$ & \multicolumn{2}{|c|}{17.5} \\
\hline T-peel strength $(\mathrm{N} / \mathrm{mm}) * *$ & \multicolumn{2}{|c|}{0.47} \\
\hline Hardness (Shore-D) & \multicolumn{2}{|c|}{82} \\
\hline Linear expansion coefficient $\left(\times 10^{-5}\right)$ & \multicolumn{2}{|c|}{67} \\
\hline Glass transition temperature $\left({ }^{\circ} \mathrm{C}\right)$ & \multicolumn{2}{|c|}{43} \\
\hline Volume resistivity $(\Omega . \mathrm{cm})$ & \multicolumn{2}{|c|}{$3.8 \times 10^{11}$} \\
\hline Water absorption (\%) & \multicolumn{2}{|c|}{2.3} \\
\hline
\end{tabular}

ๆ Manufacturer's catalogue

* JIS K6850

** JIS K6854

Table 2 Mechanical properties of materials.

\begin{tabular}{|l|r|r||r|}
\hline Material & $E(\mathrm{GPa})$ & $\sigma_{\mathrm{y}}(\mathrm{MPa})$ & \multicolumn{1}{|l|}{} \\
\hline \hline Epoxy adhesive & 3.4 & 36.5 & 0.396 \\
\hline SUS304* & 206 & 307.8 & 0.3 \\
\hline YH75 (Al-alloy)* & 71 & 559.0 & 0.33 \\
\hline
\end{tabular}

*data taken from manufacturer's catalogue 
Table 3 Order of singularity at interface corners

\begin{tabular}{|c|c|c|c|c|}
\hline \multirow{2}{*}{ Degree } & \multicolumn{4}{|c|}{ Position } \\
\cline { 2 - 5 } & $\lambda_{\mathrm{A}}$ & $\lambda_{\mathrm{B}}$ & $\lambda_{\mathrm{A}^{\prime}}$ & $\lambda_{\mathrm{B}^{\prime}}$ \\
\hline \hline $90^{\circ}$ & 0.3289 & 0.2963 & 0.2963 & 0.3289 \\
\hline $75^{\circ}$ & 0.3648 & 0.3069 & 0.2369 & 0.2545 \\
\hline $60^{\circ}$ & 0.3619 & 0.2532 & 0.1179 & 0.1242 \\
\hline $45^{\circ}$ & 0.2796 & 0.0000 & 0.0000 & 0.0000 \\
\hline $0^{\circ}$ (shear) & 0.2963 & 0.3623 & 0.3289 & 0.3534 \\
\hline
\end{tabular}

Table $4 \hat{H}_{c}$ and standard deviation calculated for specimens having $0.1 \mathrm{~mm}$ bond thickness (i.e. Series B).

\begin{tabular}{|c|c|c|c|c|c|}
\hline Degree & $\lambda_{\max }$ & $\begin{array}{c} \\
(\alpha=0.9, \beta=\alpha / 4)\end{array}$ & $\begin{array}{c}\hat{H}_{c} \\
{\left[\mathrm{MPa} . \mathrm{mm}^{\lambda}\right]}\end{array}$ & $\begin{array}{c}\text { Std Dev* } \\
{\left[\mathrm{MPa} \cdot \mathrm{mm}^{\lambda}\right]}\end{array}$ & Std Dev/ $\hat{H}_{c}(\%)$ \\
\hline $90^{\circ}$ & 0.3289 & 0.4876 & 5.1494 & 1.7950 & 34.86 \\
\hline $75^{\circ}$ & 0.3648 & 0.3101 & 3.0609 & 0.7092 & 23.17 \\
\hline $60^{\circ}$ & 0.3619 & 0.1856 & 2.0541 & 0.5229 & 25.46 \\
\hline $45^{\circ}$ & 0.2796 & 0.2953 & 4.9061 & 1.3424 & 27.36 \\
\hline $0^{\circ}$ (shear) & 0.3623 & 0.3960 & 1.2243 & 0.2882 & 23.54 \\
\hline
\end{tabular}

*Std Dev is standard deviation 


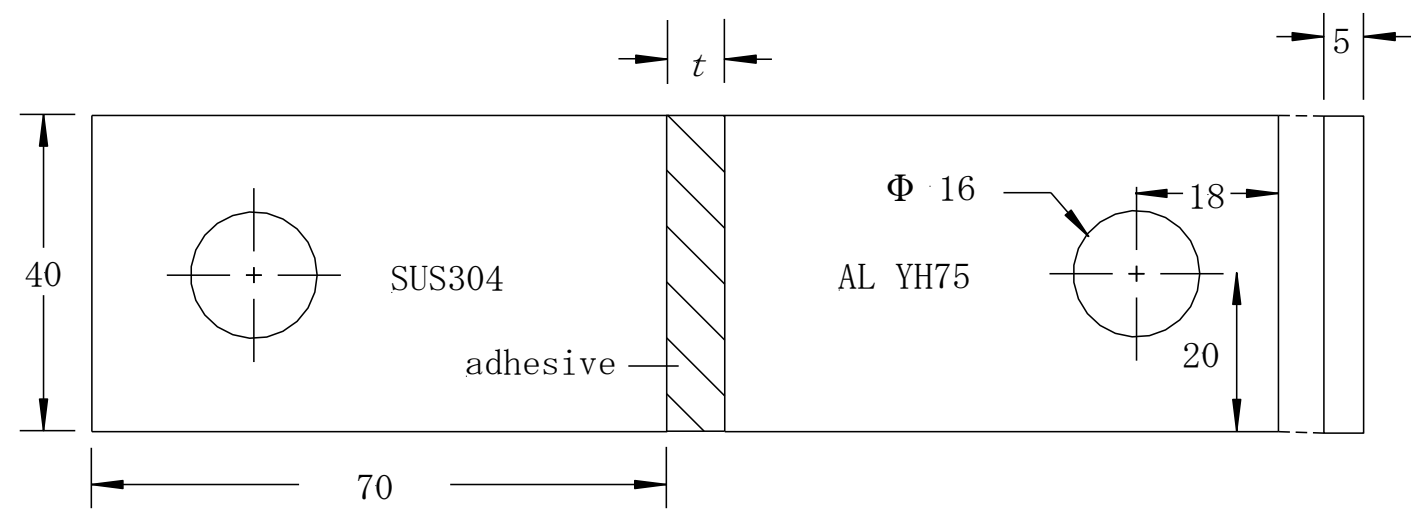

(a) Butt joint

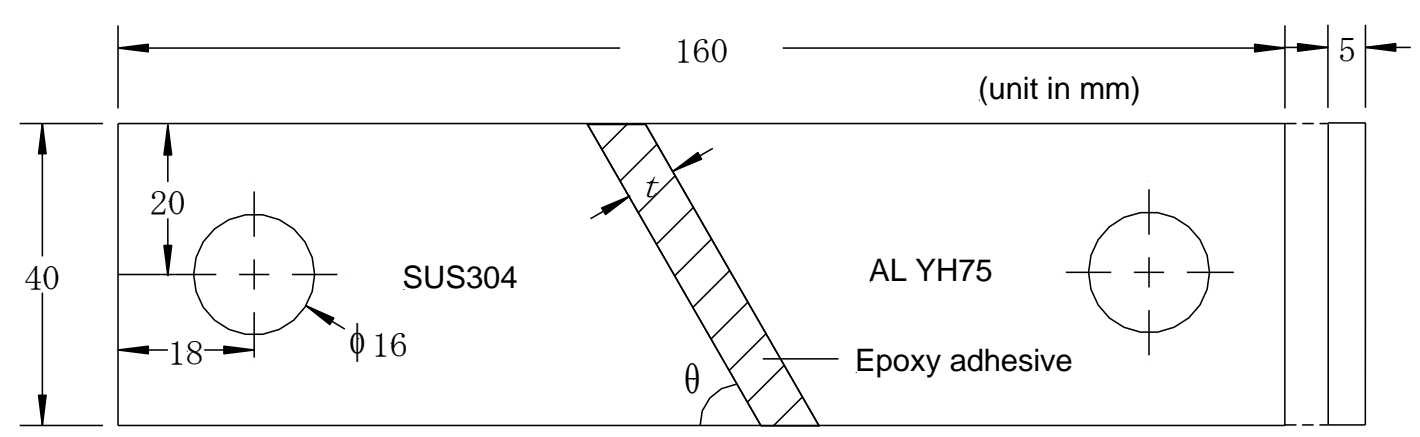

(b) Scarf joint

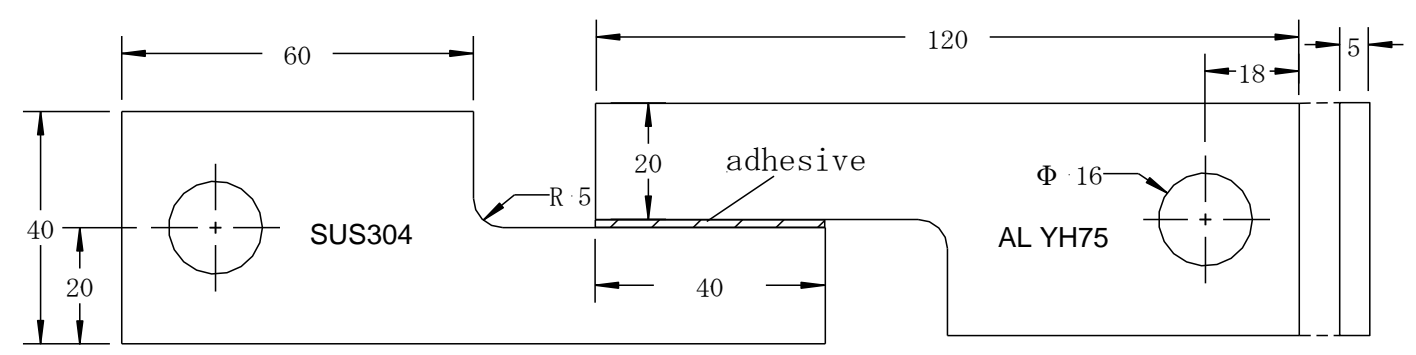

(c) Shear joint

Fig. 1 Geometry and dimensions of adhesive joint specimen. 


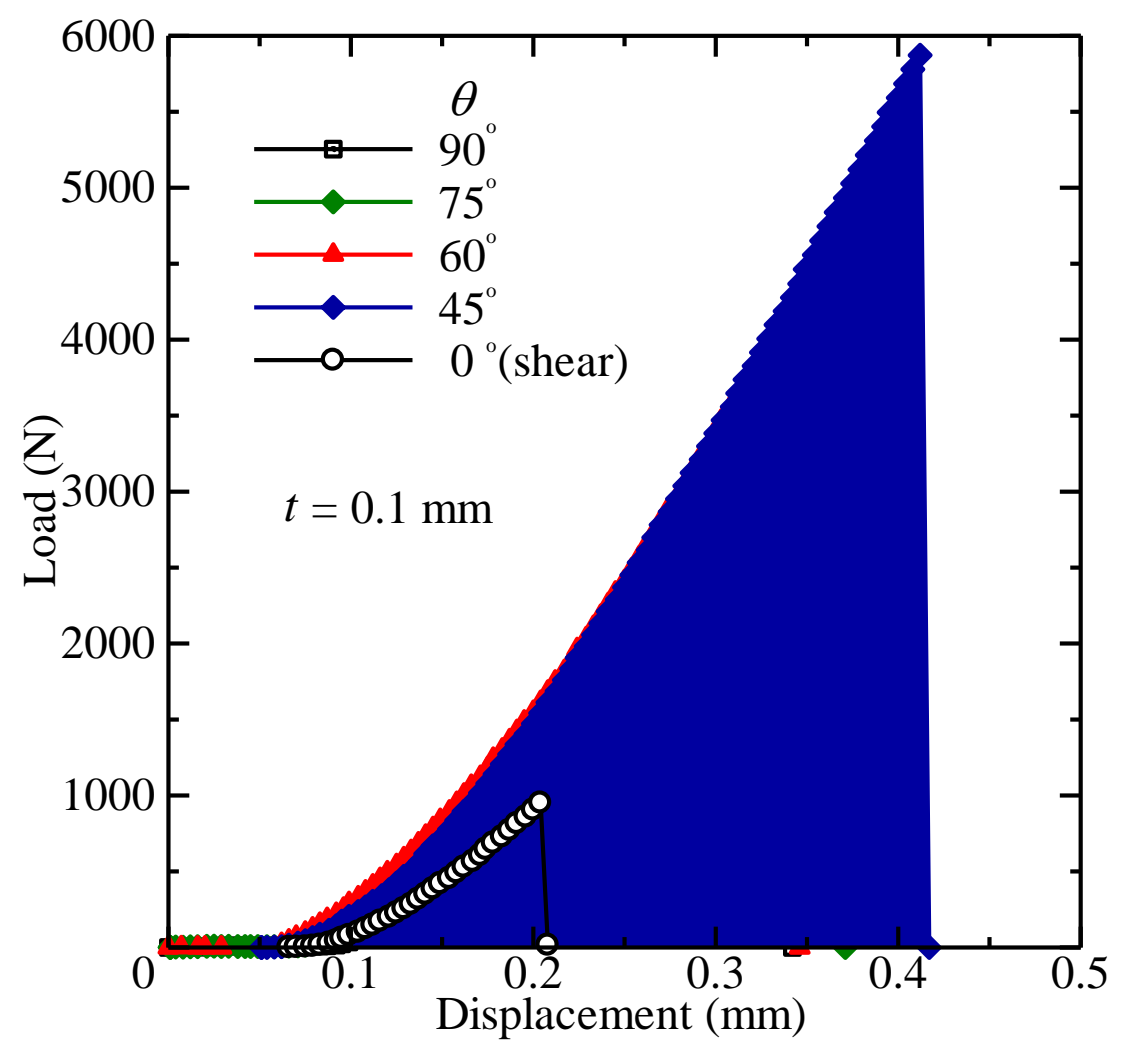

(a) $0.1 \mathrm{~mm}$ bond thickness

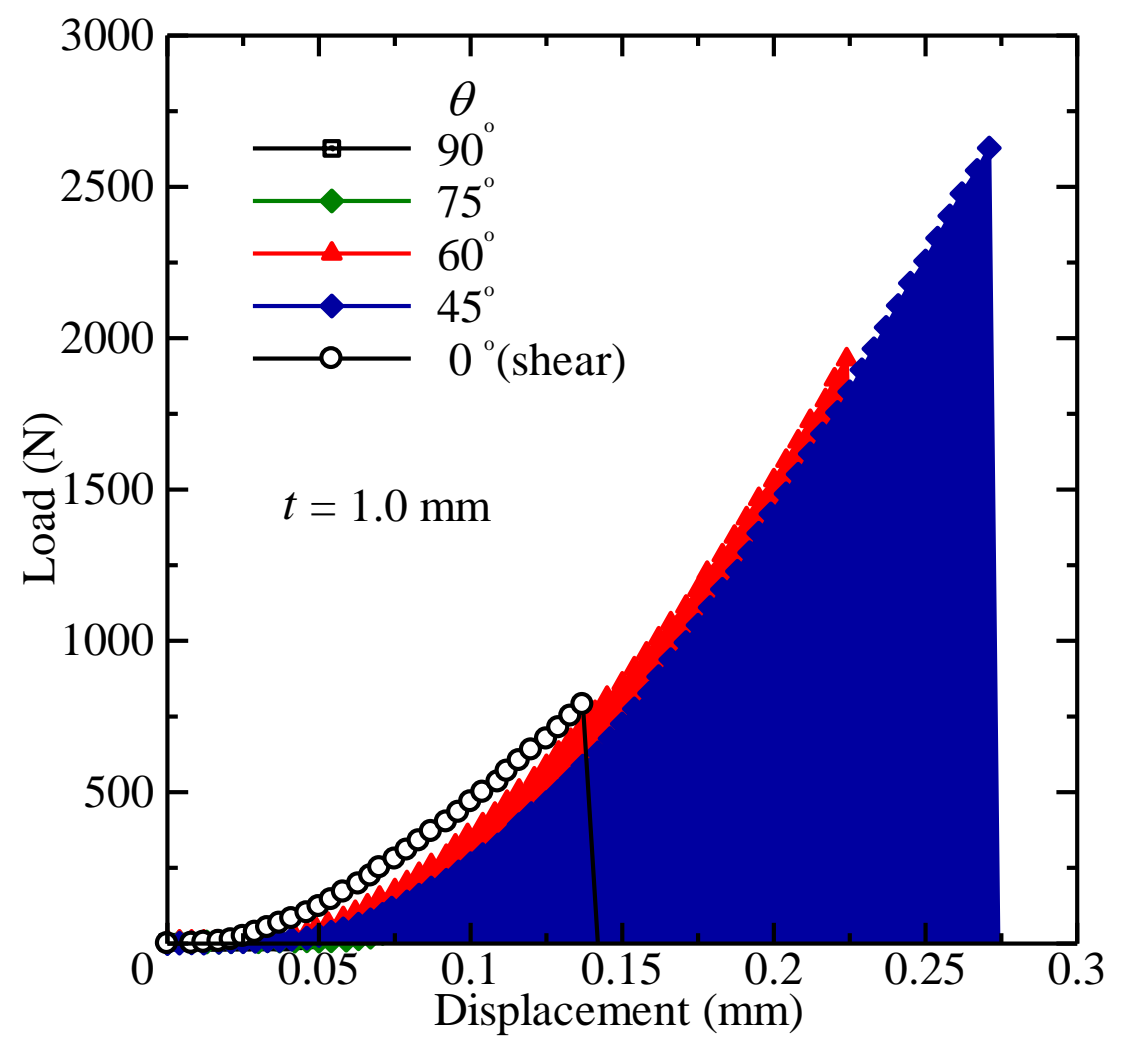

(b) $1.0 \mathrm{~mm}$ bond thickness

Fig. 2 Load versus displacement of various adhesive joints in tensile or shear tensile tests. 

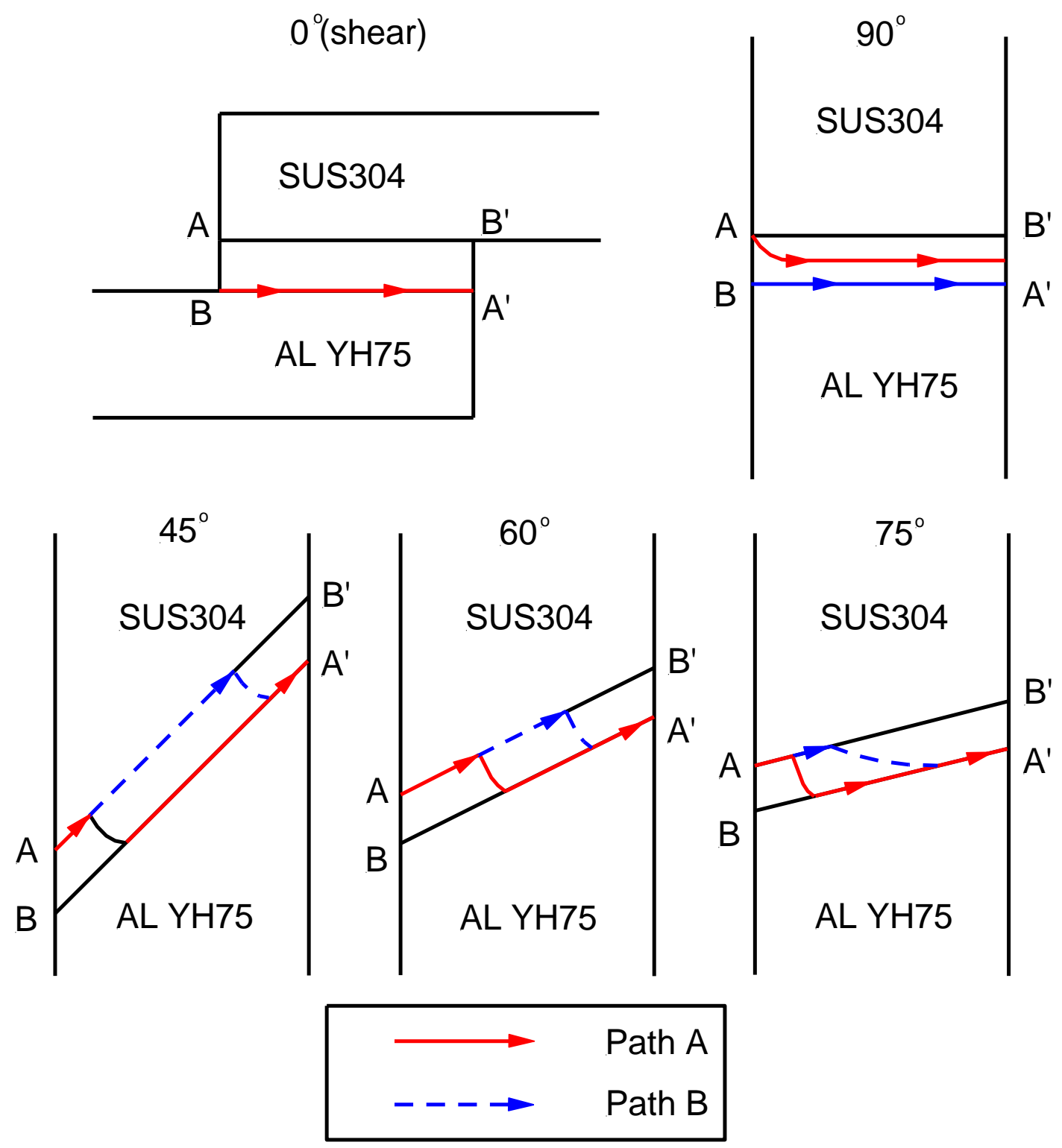

Fig. 3 Schematics of the observed failure paths 


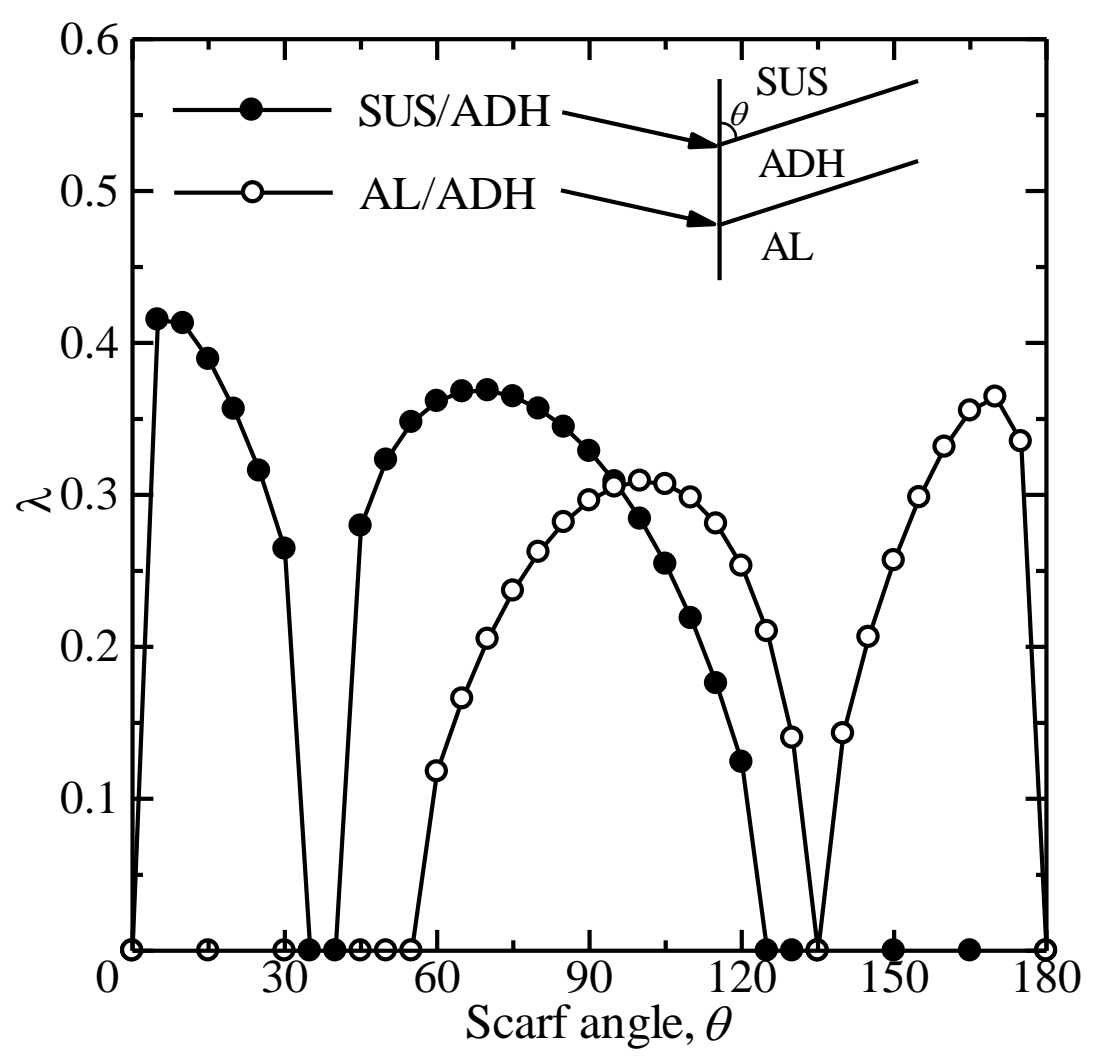

Fig. 4 Order of stress singularity, $\lambda$ at interface corner.

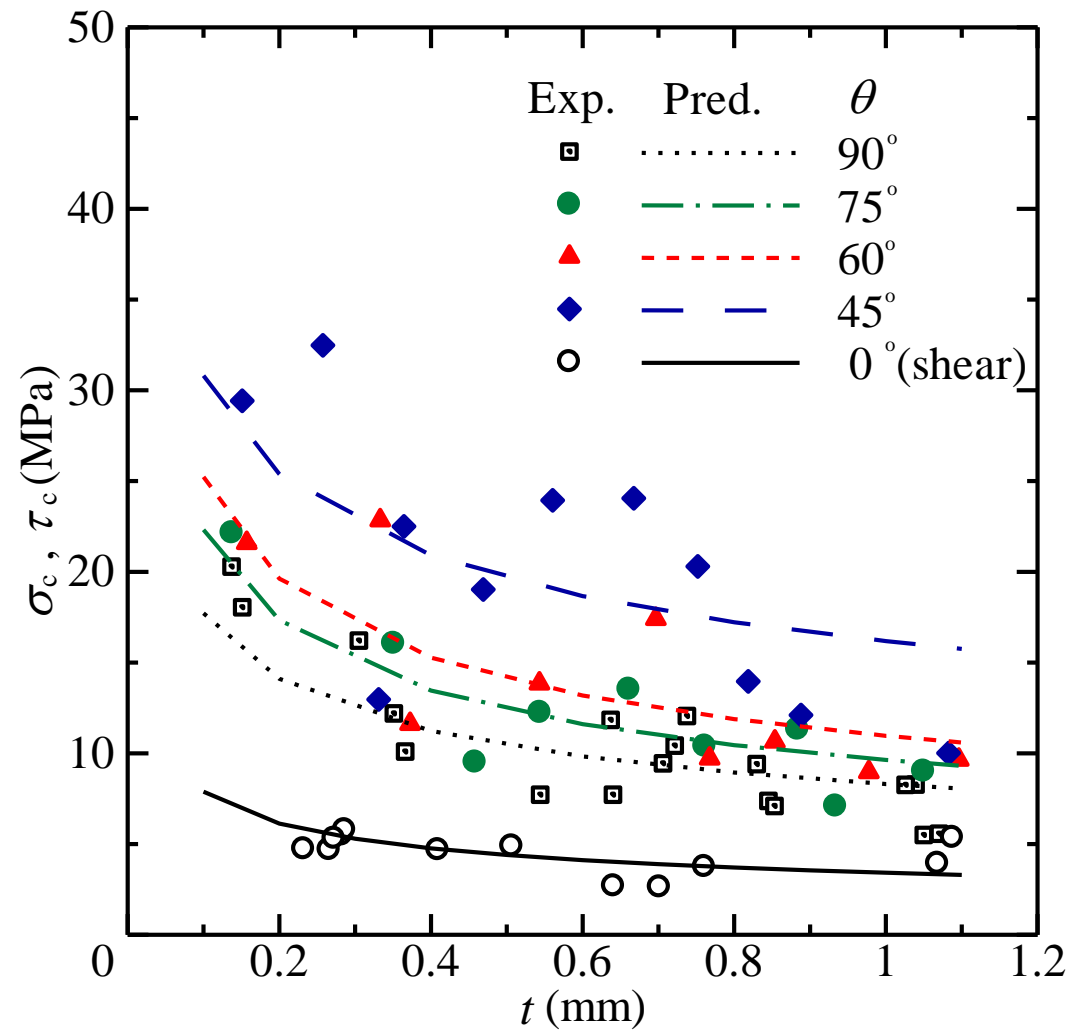

Fig. 5 Critical failure stress or critical shear stress against bond thickness. 


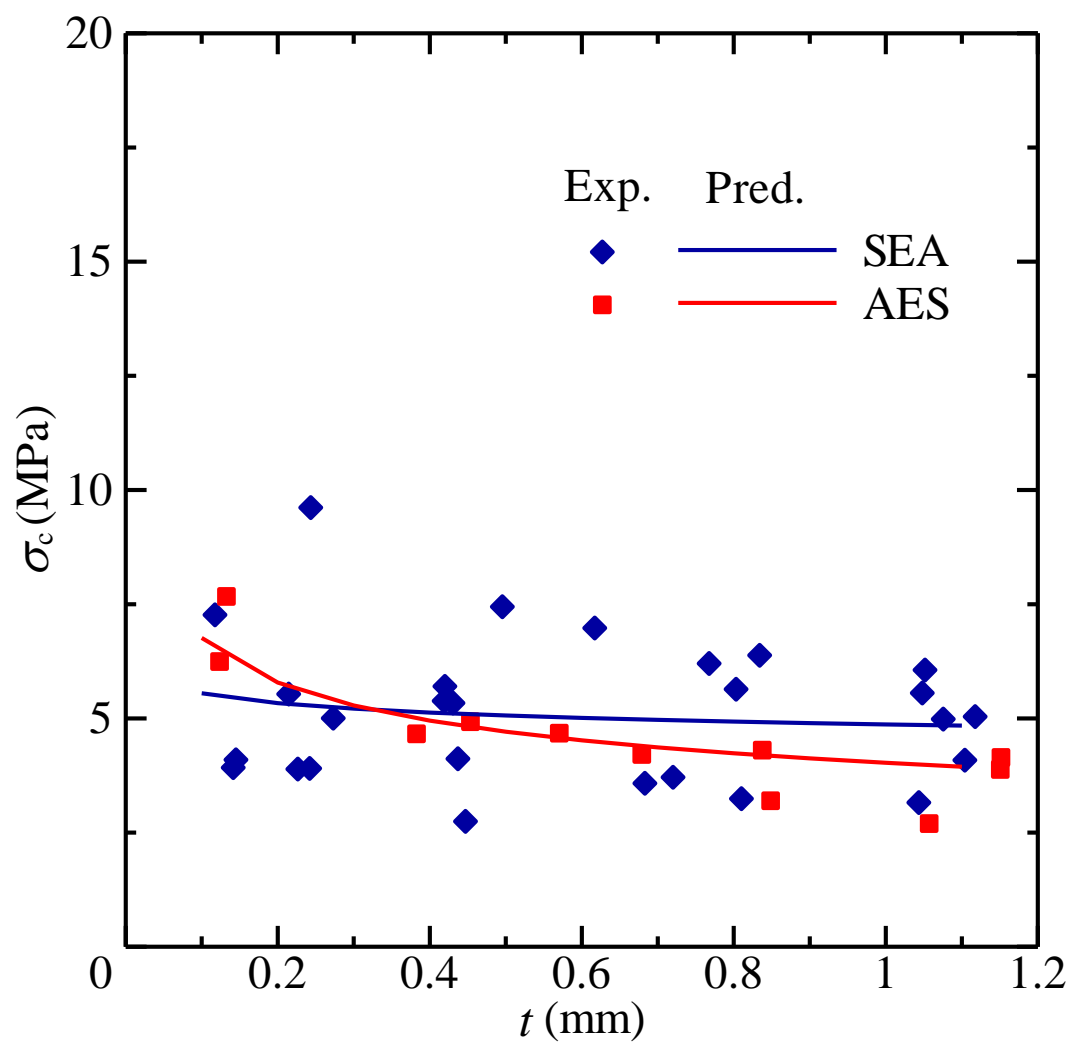

Fig. 6 Prediction of fracture stress against bond thickness for butt joint with an interfacial crack based on $J_{c}$ parameter. 


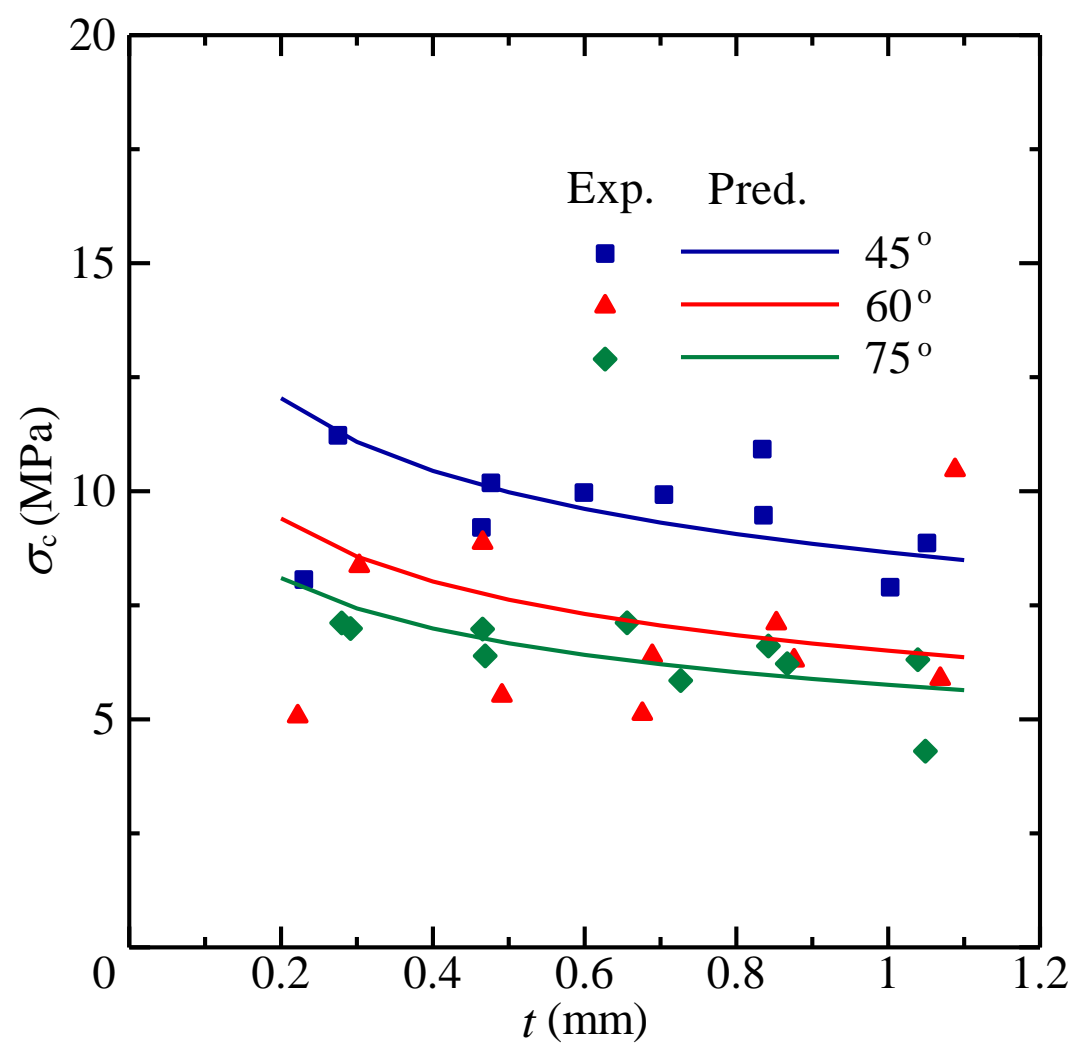

(a) SEA

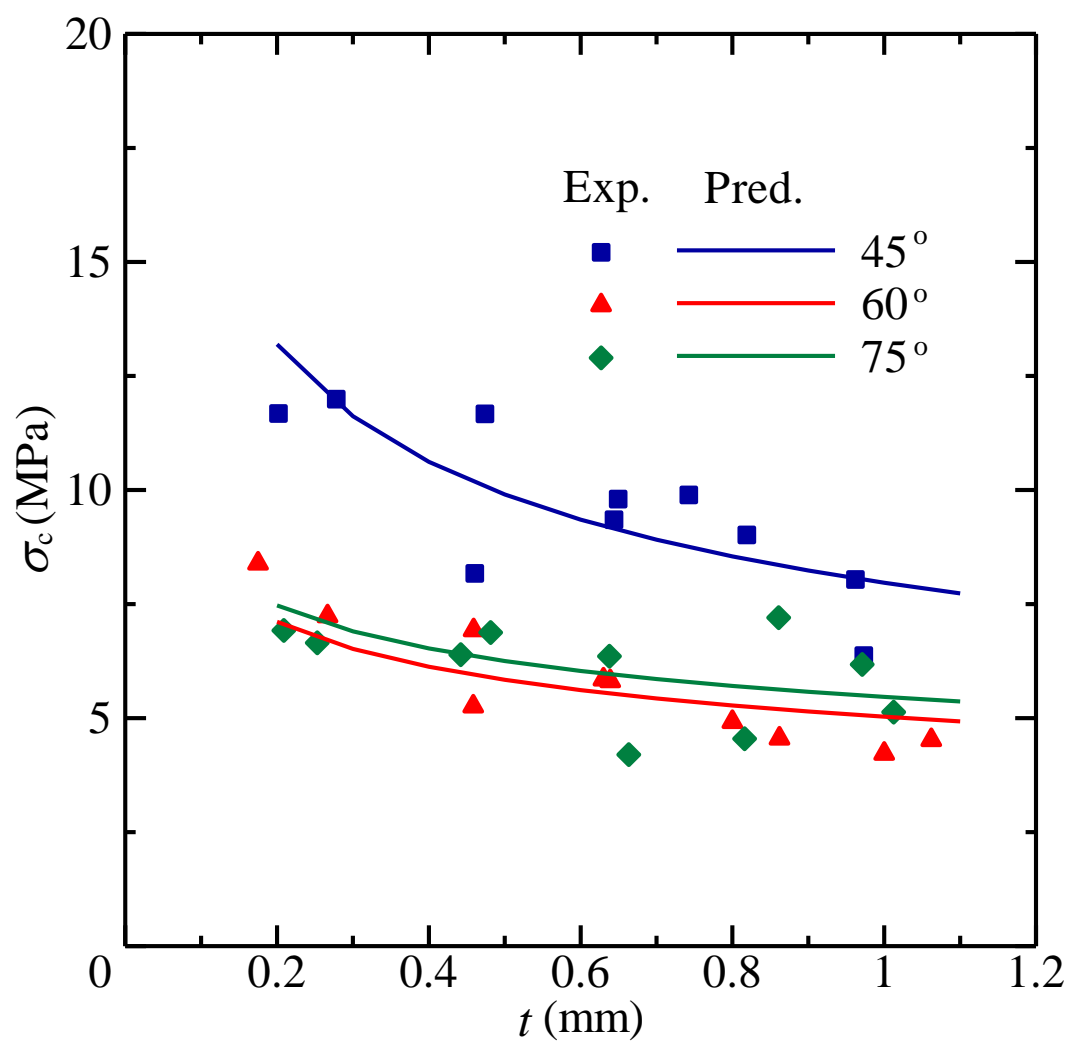

(b) AES

Fig. 7 Prediction of fracture stress against bond thickness for scarf joint with an interfacial crack, (a) SEA and (b) AES. 


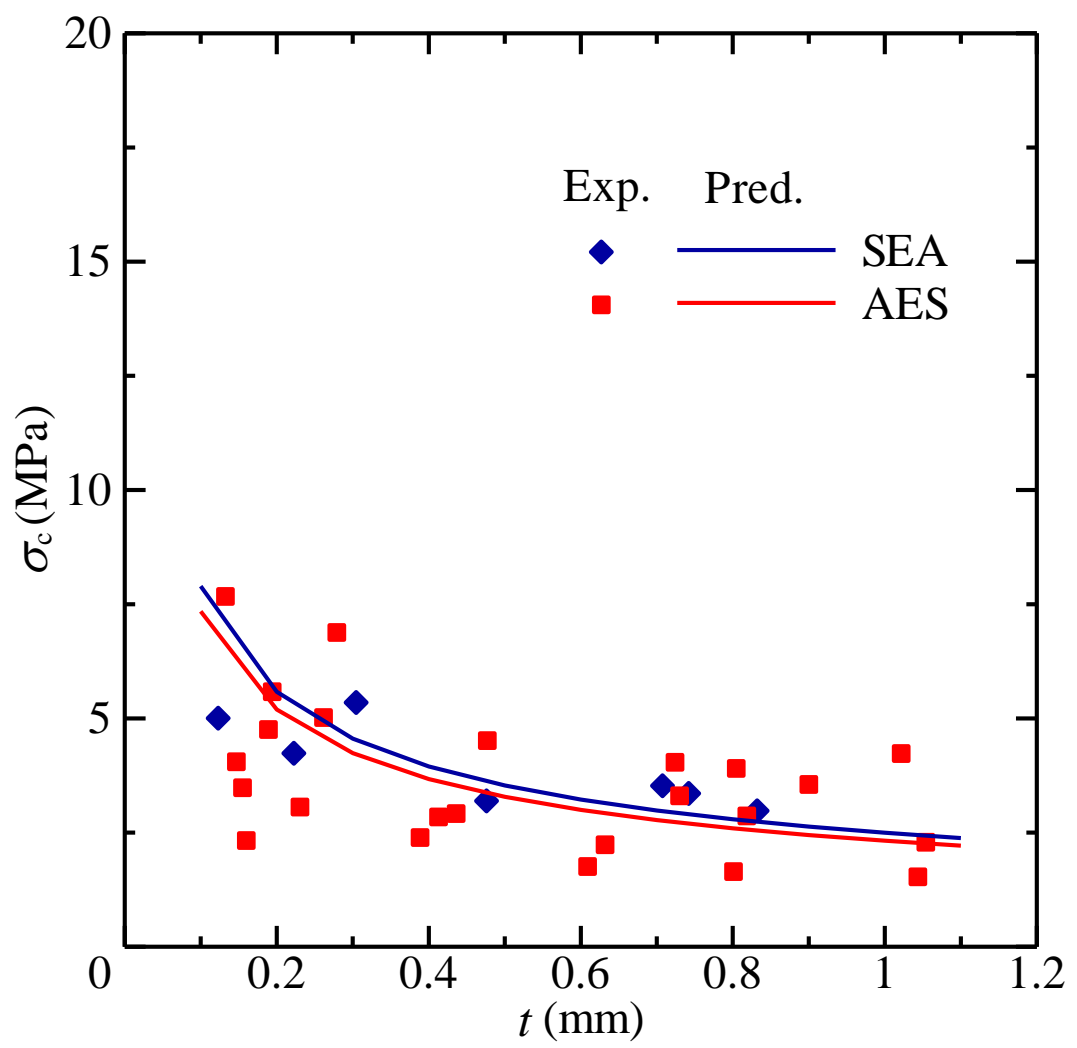

Fig. 8 Prediction of fracture stress against bond thickness in butt joint with an interfacial crack based on $K_{c}$ parameter. 


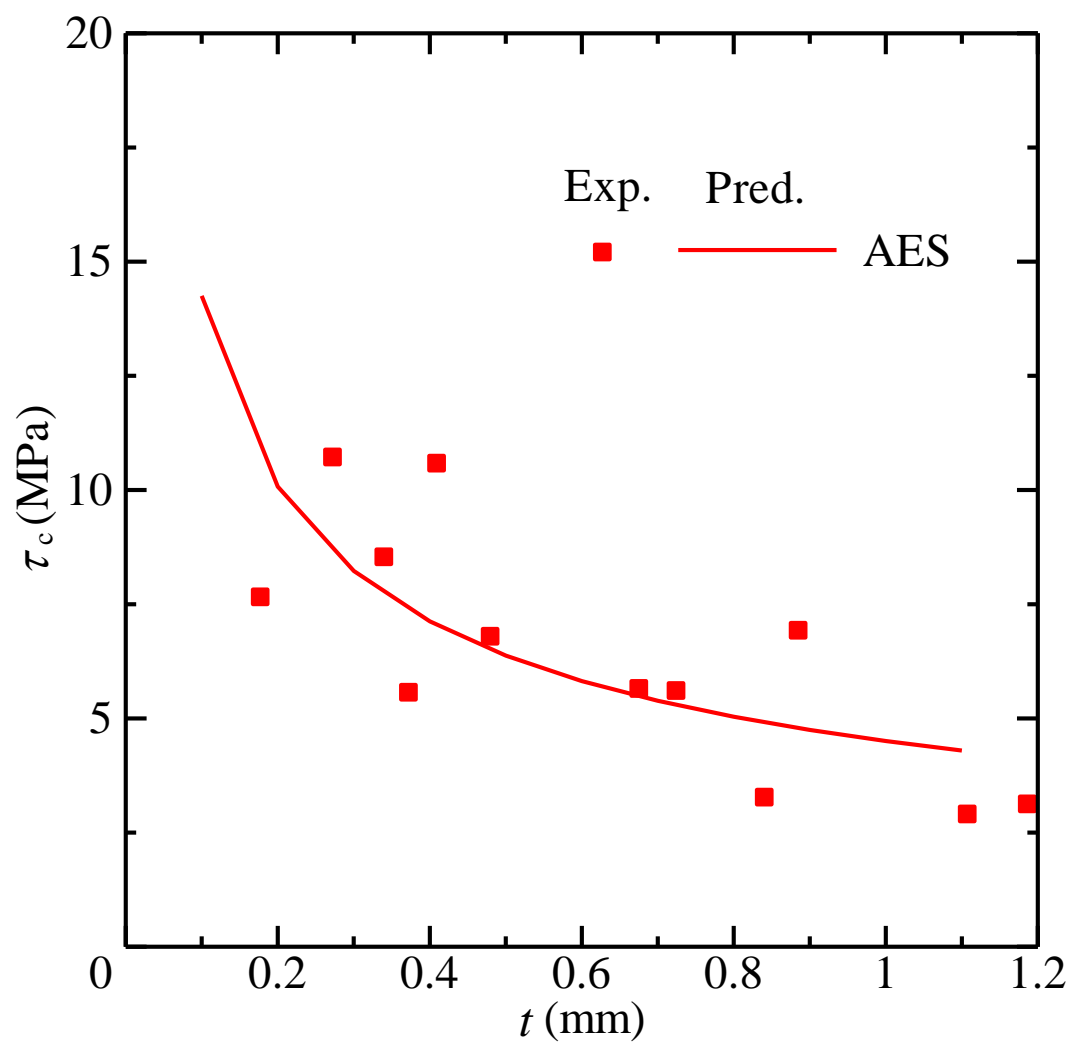

Fig. 9 Prediction of failure stress against bond thickness in shear joint based on $K_{c}$ parameter. 


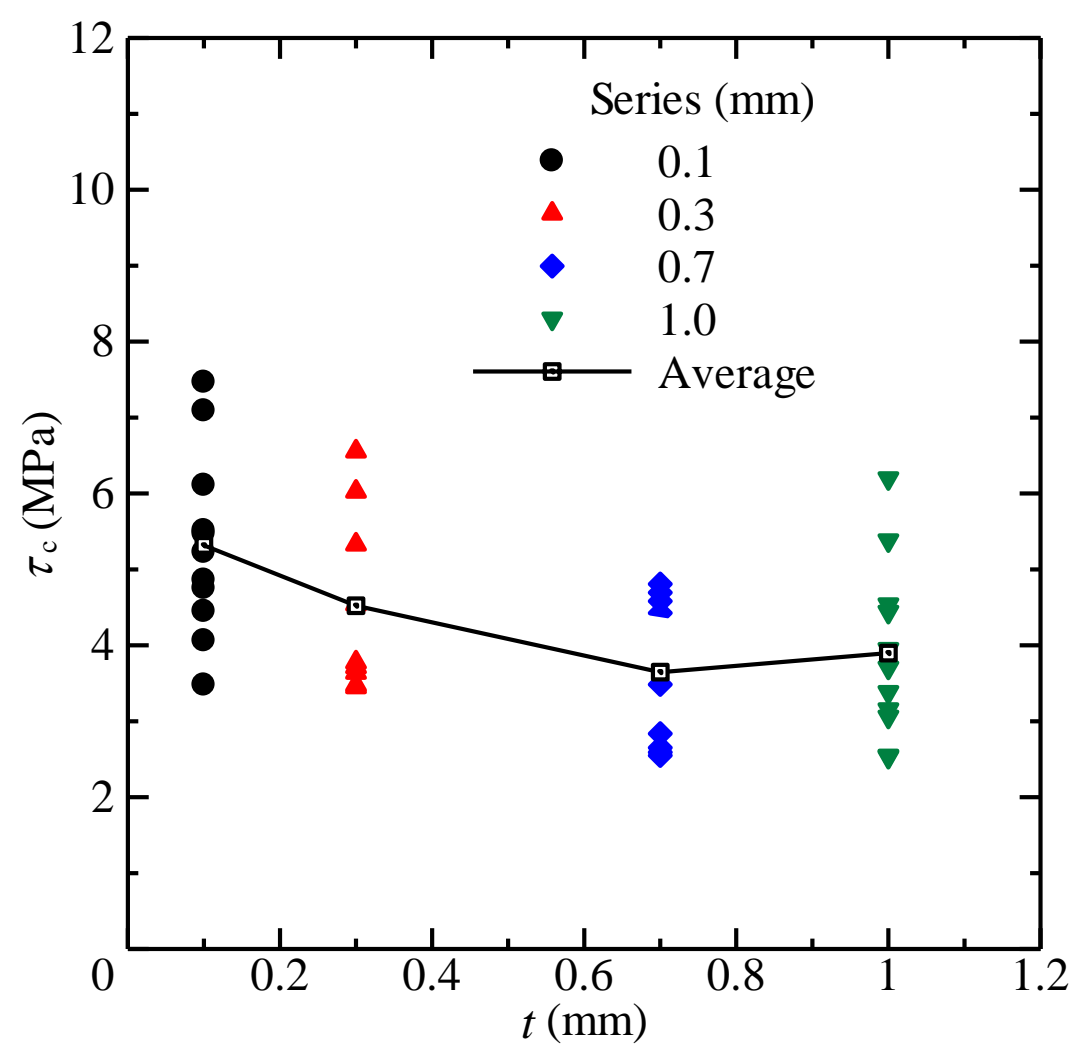

(a) Failure stress against bond thickness

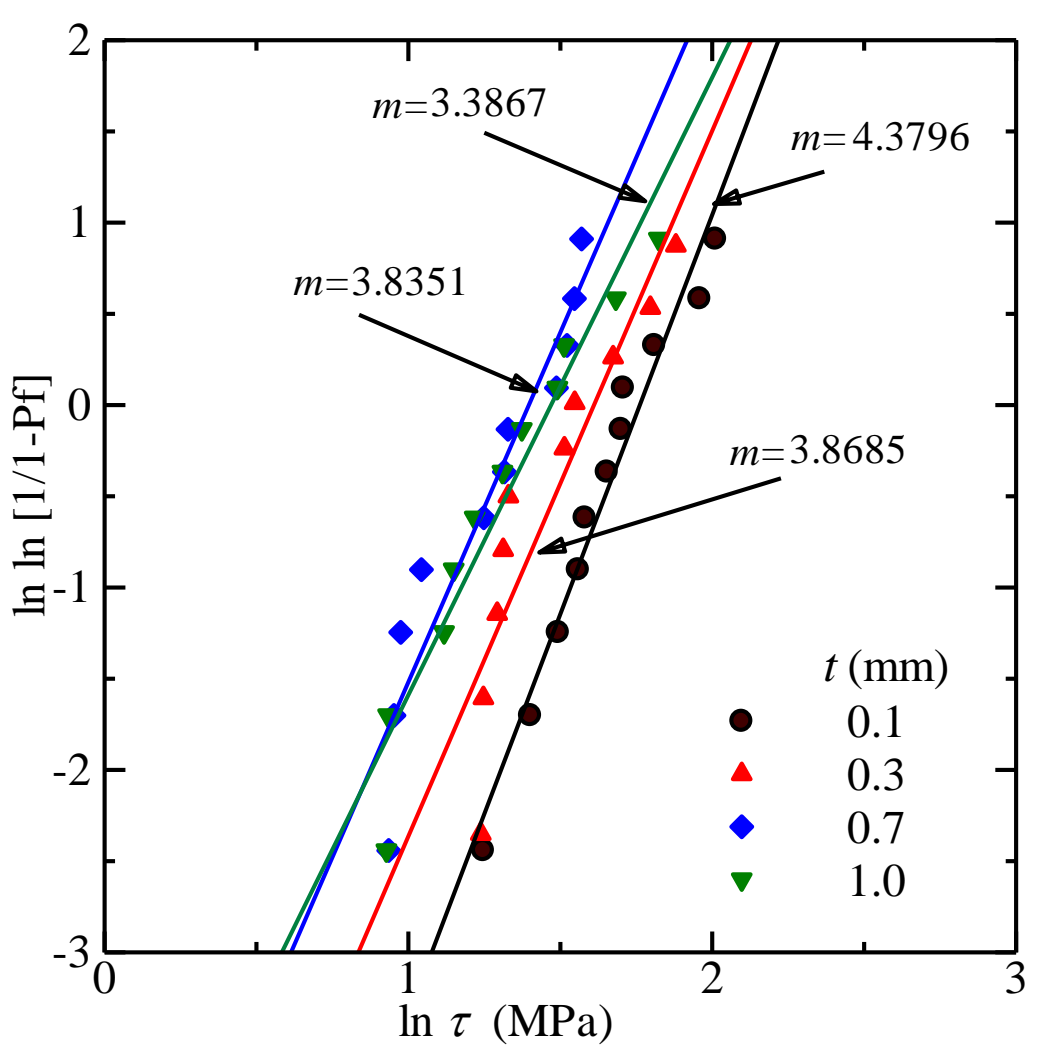

(b) Weibull plots 


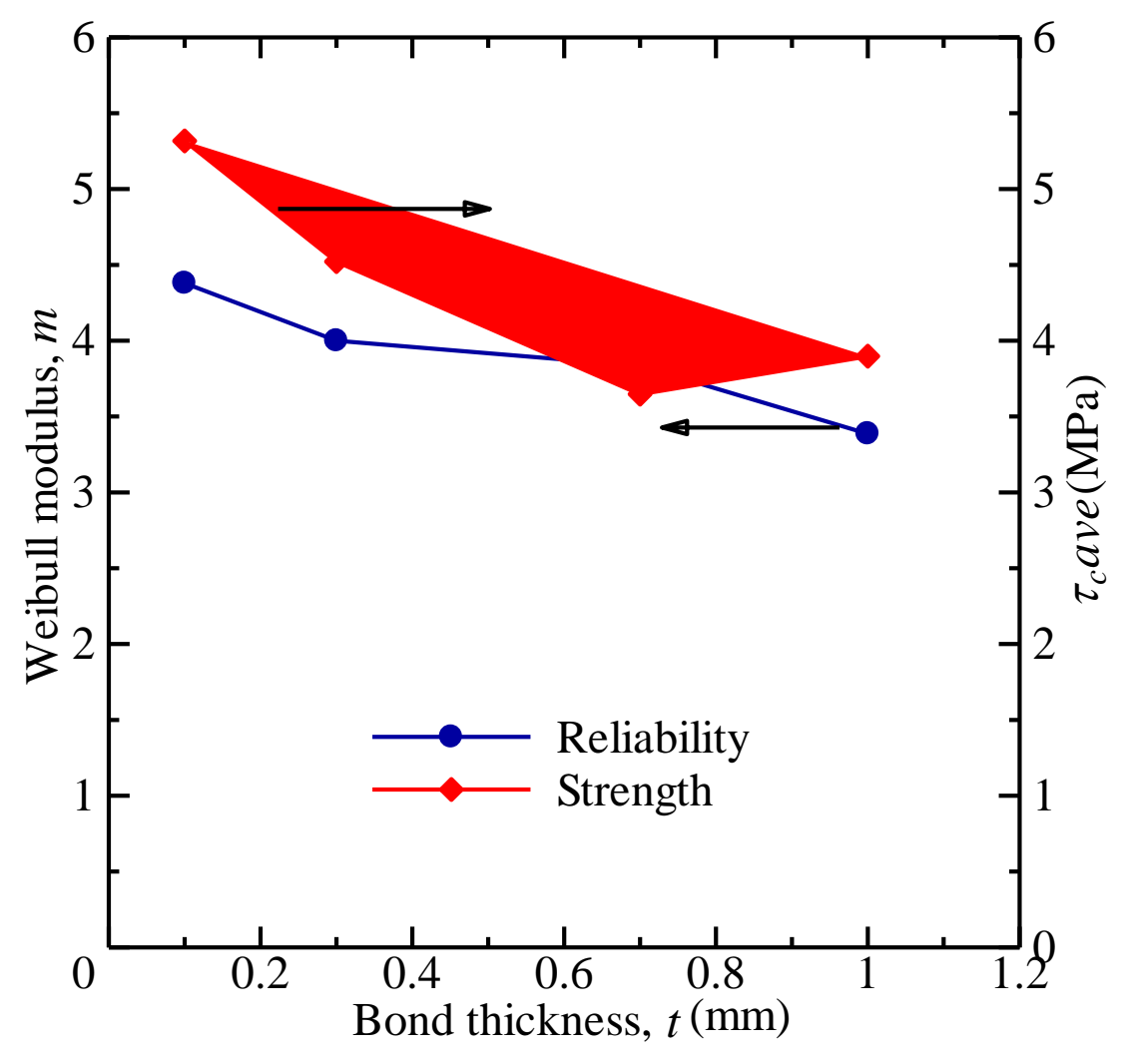

(c) Weibull modulus and average failure stress against bond thickness

Fig. 10 Weibull strength analysis of shear joint. 


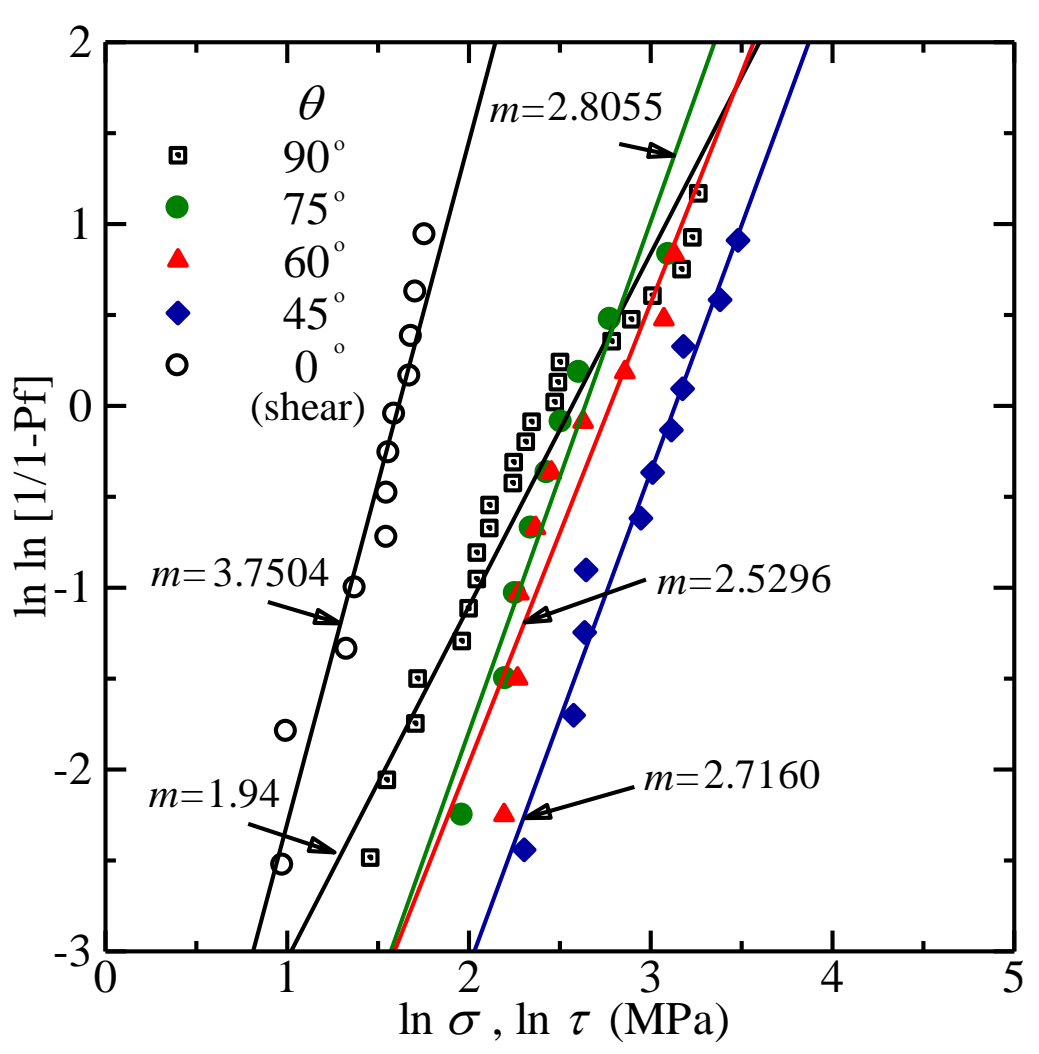

(a) Series A

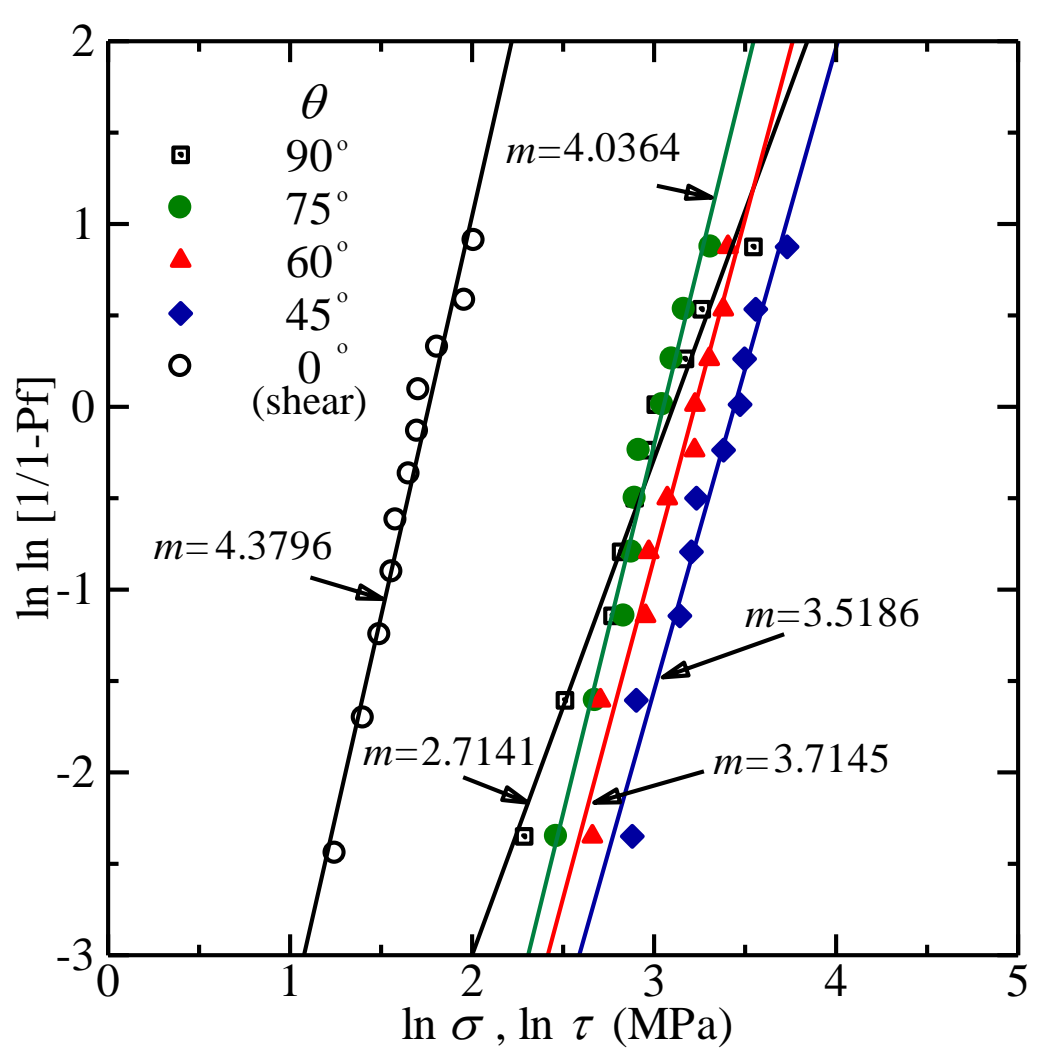

(b) Series B

Fig. 11 Logarithmic Weibull plots of adhesive joint specimens. 


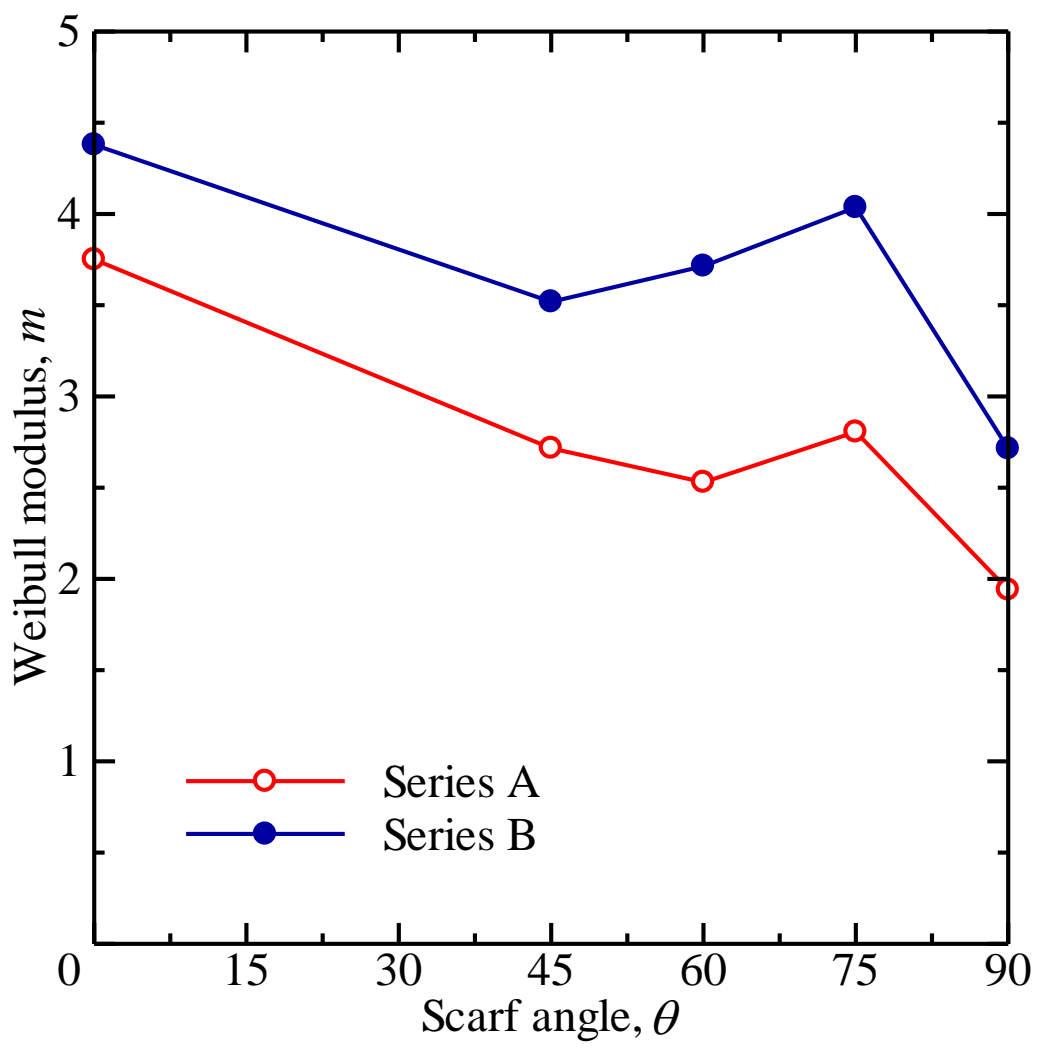

Fig. 12 Weibull modulus against various scarf angles. 